\title{
Nearly One Dimensional Singularities of Solutions to the Navier-Stokes Inequality
}

Vladimir Scheffer ${ }^{\star}$

Department of Mathematics, Rutgers University, New Brunswick, New Jersey 08903, USA

\begin{abstract}
There exists a function $u$ satisfying (1) $u$ is a weak solution to the Navier-Stokes equations of incompressible fluid flow in three-space with an external force that reduces the speed at every point, (2) the internal singularities of $u$ have Hausdorff dimension close to 1 .
\end{abstract}

\section{Section 1. Introduction}

The theorem below is an improvement on Theorem 1.1 of [4]. The difference between the two theorems is in the size of the singular set $S$. This set consisted of only one point in [4]. In the present paper, the Hausdorff dimension of $S$ is nearly one. In what follows, the laplacian $\Delta$ and the gradient $\nabla$ of a function defined on a subset of $R^{3} \times R$ will involve only the $R^{3}$ variables.

Theorem. If $\zeta<1$ then there exists a Cantor set $S \subset R^{3} \times\{1\}$ and there exist functions $u: R^{3} \times[0, \infty) \rightarrow R^{3}$ and $p: R^{3} \times[0, \infty) \rightarrow R$ satisfying the following properties:

there is a compact set $K \subset R^{3}$ such that $u(x, t)=0$ for all $x \notin K$,

for fixed $t$, the function $u_{t}: R^{3} \rightarrow R^{3}$ defined by $u_{t}(x)$

$=u(x, t)$ is a $C^{\infty}$ function,

$$
\sum_{i=1}^{3}\left(\partial u_{i} / \partial x_{i}\right)(x, t)=0
$$

$$
p(x, t)=\int_{R^{3}} \sum_{i=1}^{3} \sum_{j=1}^{3}\left(\partial u_{j} / \partial x_{i}\right)(y, t)\left(\partial u_{i} / \partial x_{j}\right)(y, t)(4 \pi|x-y|)^{-1} d y
$$

there exists $M<\infty$ such that $\left\|u_{t}\right\|_{2}<M$ for all $t\left(u_{t}\right.$ defined in (1.2)),

$$
|\nabla u|^{2},|u|^{3} \text { and }|u||p| \text { are integrable, }
$$

\footnotetext{
* The author was supported in part by a Sloan Foundation Fellowship
} 
if $\phi: R^{3} \times(0, \infty) \rightarrow R$ is a $C^{\infty}$ function with compact support and $\phi \geqq 0$, then

$$
\int_{0}^{\infty} \int_{R^{3}}|\nabla u|^{2} \phi \leqq \int_{0}^{\infty} \int_{R^{3}}\left(2^{-1}|u|^{2}+p\right) u \cdot \nabla \phi+\int_{0}^{\infty} \int_{R^{3}} 2^{-1}|u|^{2}\left(\frac{\partial \phi}{\partial t}+\Delta \phi\right),
$$

$u$ is not essentially bounded on any neighborhood of any point in $S$,

the Hausdorff dimension of $S$ is greater than $\zeta$.

The introduction of [4] contains a discussion of the heuristics of this type of theorem. Briefly, we are interested in solutions to

$$
\begin{array}{r}
\frac{\partial}{\partial t} u_{i}=-\sum_{j=1}^{3} u_{j} \frac{\partial u_{i}}{\partial x_{j}}-\frac{\partial p}{\partial x_{i}}+\Delta u_{i}+f_{i}, \\
\sum_{i=1}^{3} \frac{\partial u_{i}}{\partial x_{i}}=0, \quad \sum_{i=1}^{3} \frac{\partial f_{i}}{\partial x_{i}}=0, \quad \sum_{i=1}^{3} f_{i} u_{i} \leqq 0 .
\end{array}
$$

This says that $u$ is a solution to the Navier-Stokes equations of incompressible fluid flow with an external force $f$ that is divergence free and pushes against the flow at every point of space-time. Properties (1.3), (1.4), (1.7) say that (1.10) is satisfied in a weak sense. The right definition of weak solution is obtained by multiplying (1.10) by a nonnegative test function $\phi$ and integrating.

It can be shown that the theorem in this paper is nearly optimal. The proof of Theorem 2.1 of [3] implies that the intersection of the singular set with any hyperplane of the form $R^{3} \times\{t\}$ cannot have dimension greater than 1 . Therefore, the conditions stated in the theorem (which include $S \subset R^{3} \times\{1\}$ ) always force $\operatorname{dim}(S) \leqq 1$. Furthermore, L. Caffarelli, R. Kohn and L. Nirenberg proved, in a slightly different context, that it is not possible to increase the dimension of $S$ beyond 1 by relaxing the requirement $S \subset R^{3} \times\{1\}$. This result appears in [1].

\section{Section 2. Preliminaries}

We recall some of the notation of [4]. The set of $C^{\infty}$ functions with compact support from $U$ into $R^{n}$ will be denoted by $C_{c}^{\infty}\left(U, R^{n}\right)$. The support of a function $f$ will be written $\operatorname{spt}(f)$. We set $P=\left\{\left(x_{1}, x_{2}\right) \in R^{2}: x_{2}>0\right\}$. If $c=\left(c_{1}, c_{2}\right) \in R^{2}$ and $c_{1}^{2}+c_{2}^{2}=1$, then $R_{c}: R^{3} \rightarrow R^{3}$ is the rotation

$$
R_{c}\left(x_{1}, x_{2}, x_{3}\right)=\left(x_{1}, c_{1} x_{2}-c_{2} x_{3}, c_{1} x_{3}+c_{2} x_{2}\right)
$$

about the $x_{1}$ axis. If $f \in C_{c}^{\infty}(P, R), v=\left(v_{1}, v_{2}\right) \in C_{c}^{\infty}\left(P, R^{2}\right), f \geqq 0$ and $f(x)>|v(x)|$ holds for all $x \in \operatorname{spt}(v)$, then $u[v, f] \in C_{c}^{\infty}\left(R^{3}, R^{3}\right)$ is defined by

$$
u[v, f]\left(x_{1}, x_{2}, 0\right)=\left(v_{1}\left(x_{1}, x_{2}\right), v_{2}\left(x_{1}, x_{2}\right),\left(\left(f\left(x_{1}, x_{2}\right)\right)^{2}-\left|v\left(x_{1}, x_{2}\right)\right|^{2}\right)^{1 / 2}\right)
$$

if $\left(x_{1}, x_{2}\right) \in P$,

$$
u[v, f]\left(R_{c}\left(x_{1}, x_{2}, 0\right)\right)=R_{c}\left(u[v, f]\left(x_{1}, x_{2}, 0\right)\right) \quad \text { if } \quad c \in R^{2},|c|=1, \quad\left(x_{1}, x_{2}\right) \in P,
$$

and $u[v, f]\left(x_{1}, 0,0\right)=0$. Under the same hypotheses, we define $p^{*}[v, f]: R^{3} \rightarrow R$ 
and $p[v, f]: P \rightarrow R$ by means of

$$
p^{*}[v, f](x)=\int_{R^{3}} \sum_{i=1}^{3} \sum_{j=1}^{3}\left(\frac{\partial}{\partial x_{i}} u_{j}[v, f]\right)(y)\left(\frac{\partial}{\partial x_{j}} u_{i}[v, f]\right)(y)(4 \pi|x-y|)^{-1} d y,
$$

and $p[v, f]\left(x_{1}, x_{2}\right)=p^{*}[v, f]\left(x_{1}, x_{2}, 0\right)$. If $f \in C_{c}^{\infty}(P, R)$, we set

$$
\begin{aligned}
L(f)\left(x_{1}, x_{2}\right)= & \Delta f\left(x_{1}, x_{2}\right)+x_{2}^{-1}\left(\partial f / \partial x_{2}\right)\left(x_{1}, x_{2}\right) \\
& -x_{2}^{-2} f\left(x_{1}, x_{2}\right) \text { if }\left(x_{1}, x_{2}\right) \in P .
\end{aligned}
$$

If $A$ and $B$ are sets then we set $A \sim B=\{x \in A: x \notin B\}$. If $f_{i}$ is a function defined on a subset of $R^{3} \times R$, then we will write $f_{i, t}(x) \equiv f_{i}(x, t)$ for appropriate $(x, t) \in R^{3} \times R$. This notation is used in Sect. 3 and Sect. 5 for the functions $h_{i}^{m}, q_{i}^{m, k}$ and $h_{i}$. However, this does not apply to the function $F_{i, j}^{m, n}$ in Lemma 3.1 .

The functions $u[v, f], p^{*}[v, f], p[v, f]$ will only be used when $v$ satisfies

$$
x_{2} \frac{\partial}{\partial x_{1}} v_{1}\left(x_{1}, x_{2}\right)+x_{2} \frac{\partial}{\partial x_{2}} v_{2}\left(x_{1}, x_{2}\right)+v_{2}\left(x_{1}, x_{2}\right)=0 \text {. }
$$

This equation implies $\operatorname{div}(u[v, f])=0$.

Lemma 2.1. We have $p[v, f]=p[-v, f]$ if the left side makes sense.

Proof. If $u: R^{3} \rightarrow R^{3}$ satisfies $u\left(R_{c}(x)\right)=R_{c}(u(x))$, then the identity

$$
\sum_{i=1}^{3} \sum_{j=1}^{3} \frac{\partial u_{j}}{\partial x_{i}}(x) \frac{\partial u_{i}}{\partial x_{j}}(x)=\sum_{i=1}^{3} \sum_{j=1}^{3} \frac{\partial u_{j}}{\partial x_{i}}\left(R_{c}(x)\right) \frac{\partial u_{i}}{\partial x_{j}}\left(R_{c}(x)\right)
$$

follows because we can write the left side in the invariant form

$$
\sum_{i=1}^{3} \sum_{j=1}^{3} \frac{\partial u_{j}}{\partial x_{i}} \frac{\partial u_{i}}{\partial x_{j}}=\operatorname{div}(u \cdot \nabla u)-u \cdot \nabla(\operatorname{div}(u)) .
$$

If $\left(x_{1}, x_{2}\right) \in P$, then we conclude

$$
\begin{aligned}
& \sum_{i=1}^{3} \sum_{j=1}^{3}\left(\frac{\partial}{\partial x_{i}} u_{j}[v, f]\right)\left(x_{1}, x_{2}, 0\right)\left(\frac{\partial}{\partial x_{j}} u_{i}[v, f]\right)\left(x_{1}, x_{2}, 0\right) \\
& =\sum_{i=1}^{3} \sum_{j=1}^{3}\left(\frac{\partial}{\partial x_{i}} u_{j}[-v, f]\right)\left(x_{1}, x_{2}, 0\right)\left(\frac{\partial}{\partial x_{j}} u_{i}[-v, f]\right)\left(x_{1}, x_{2}, 0\right) .
\end{aligned}
$$

If $y=\left(y_{1}, y_{2}, y_{3}\right)=R_{c}\left(x_{1}, x_{2}, 0\right)$ for some $\left(x_{1}, x_{2}\right) \in P$, then all this implies

$$
\begin{aligned}
& \sum_{i=1}^{3} \sum_{j=1}^{3}\left(\frac{\partial}{\partial x_{i}} u_{j}[v, f]\right)(y)\left(\frac{\partial}{\partial x_{j}} u_{i}[v, f]\right)(y) \\
& =\sum_{i=1}^{3} \sum_{j=1}^{3}\left(\frac{\partial}{\partial x_{i}} u_{j}[-v, f]\right)(y)\left(\frac{\partial}{\partial x_{j}} u_{i}[-v, f]\right)(y) .
\end{aligned}
$$

We get $p^{*}[v, f]=p^{*}[-v, f]$ and, consequently, $p[v, f]=p[-v, f]$.

Lemma. 2.2. The identity $p[v, f]+p[w, g]=p[v+w, f+g]$ is valid if $\operatorname{spt}(f)$ and $\operatorname{spt}(g)$ are disjoint and the left side makes sense. 
Proof. This is immediate from the definition.

\section{Section 3. An Oscillatory Process}

Lemma 3.1. If $M$ is a positive integer and $T$ is a positive real number, then there exist $C^{\infty}$ functions $a_{i}^{m, k}: R \rightarrow[-1,1]$ for $i \in\{1,2\}, m \in\{1,2, \ldots, M\}, k \in\{1,2,3, \ldots\}$ such that $\operatorname{spt}\left(a_{i}^{m, k}\right) \subset[0, T]$ and the following property holds: Suppose that $G_{i}^{m}: P \times$ $[0, T] \rightarrow R$ and $F_{i, j}^{m, n}: P \times[0, T] \times[-1,1] \rightarrow R$ are uniformly continuous and bounded functions for $\{i, j\} \subset\{1,2\},\{m, n\} \subset\{1,2, \ldots, M\}$ such that the identity

$$
F_{i, j}^{m, n}(x, t, 1)=F_{i, j}^{m, n}(x, t,-1)
$$

is satisfied. Suppose, also, that the functions $H_{i}^{m, k}: P \times[0, T] \rightarrow R, H_{i}^{m}: P \times[0, T] \rightarrow R$ are defined by

$$
\begin{aligned}
H_{i}^{m, k}(x, s) & =\int_{0}^{s} a_{i}^{m, k}(t)\left(G_{i}^{m}(x, t)+\sum_{j=1}^{2} \sum_{n=1}^{M} F_{i, j}^{m, n}\left(x, t, a_{j}^{n, k}(t)\right)\right) d t \\
H_{1}^{m}(x, s) & =0, \quad H_{2}^{m}(x, s)=\int_{0}^{s} 2^{-1}\left(F_{2,1}^{m, m}(x, t, 1)-F_{2,1}^{m, m}(x, t, 0)\right) d t .
\end{aligned}
$$

Then $H_{i}^{m, k}$ converges to $H_{i}^{m}$ uniformly as $k$ approaches $\infty$.

Proof. Let $b_{i}^{m, k}:[0, T] \rightarrow[-1,1]$ and $c^{m, k}:[0, T] \rightarrow[0,1]$ be defined almost everywhere by the identities

$$
\begin{aligned}
& b_{1}^{m, k}(t)=1 \quad \text { if } \quad(4 p-4) 4^{-m} k^{-1} T<t<(4 p-3) 4^{-m} k^{-1} T, \\
& b_{1}^{m, k}(t)=-1 \quad \text { if } \quad(4 p-3) 4^{-m} k^{-1} T<t<(4 p-2) 4^{-m} k^{-1} T, \\
& b_{1}^{m, k}(t)=0 \quad \text { if } \quad(4 p-2) 4^{-m} k^{-1} T<t<(4 p) 4^{-m} k^{-1} T, \\
& b_{2}^{m, k}(t)=1 \quad \text { and } \quad c^{m, k}(t)=1 \quad \text { if } \quad(4 p-4) 4^{-m} k^{-1} T<t<(4 p-2) 4^{-m} k^{-1} T, \\
& b_{2}^{m, k}(t)=-1 \quad \text { and } \quad c^{m, k}(t)=0 \quad \text { if } \quad(4 p-2) 4^{-m} k^{-1} T<t<(4 p) 4^{-m} k^{-1} T
\end{aligned}
$$

for $p=1,2,3, \ldots, 4^{m-1} k$. We choose functions $a_{i}^{m, k}$ satisfying

$$
a_{i}^{m, k}: R \rightarrow[-1,1], a_{i}^{m, k} \quad \text { is } \quad C^{\infty}, \quad \operatorname{spt}\left(a_{i}^{m, k}\right) \subset[0, T],
$$

the Lebesgue measure of $\left\{t \in[0, T]: a_{i}^{m, k}(t) \neq b_{i}^{m, k}(t)\right\}$ is less than $k^{-1}$.

Let $G_{i}^{m}$ and $F_{i, j}^{m, n}$ satisfy the hypotheses of the lemma. For every positive integer $k$, we can define $\varepsilon(k)$ to be the smallest element of the interval $[0, \infty]$ satisfying

$$
\begin{aligned}
\left|F_{i, j}^{m, n}(x, t, a)-F_{i, j}^{m, n}\left(x, t^{\prime}, a\right)\right| \leqq \varepsilon(k) & \text { if } & \left|t-t^{\prime}\right| \leqq k^{-1} T \\
\left|G_{i}^{m}(x, t)-G_{i}^{m}\left(x, t^{\prime}\right)\right| \leqq \varepsilon(k) & \text { if } & \left|t-t^{\prime}\right| \leqq k^{-1} T .
\end{aligned}
$$

The uniform continuity hypothesis implies

$$
\varepsilon(k) \rightarrow 0 \quad \text { as } \quad k \rightarrow \infty .
$$

Our hypotheses also allow us to find $N$ with the properties

$$
N<\infty, \quad\left|F_{i, j}^{m, n}(x, t, a)\right| \leqq N, \quad\left|G_{i}^{m}(x, t)\right| \leqq N .
$$


Now we fix $k \in\{1,2,3, \ldots\}$ and $s \in[0, T]$. We define

$$
\begin{aligned}
t_{q}= & q k^{-1} T \text { if } q \in\{0,1,2, \ldots, k\}, S_{q}=\text { the interval }\left(t_{q-1}, t_{q}\right), \\
& Q \text { is an integer satisfying } s \in\left[t_{Q}, t_{Q+1}\right] \text { and } 0 \leqq Q \leqq k-1 .
\end{aligned}
$$

The identities in (3.3) imply

$$
\begin{aligned}
\int_{S_{q}} b_{i}^{m, k}(t) d t & =0, \quad \int_{S_{q}} b_{1}^{m, k}(t) c^{n, k}(t) d t=0, \\
\int_{S_{q}} b_{2}^{m, k}(t) c^{n, k}(t) d t & =0 \quad \text { if } \quad m \neq n, \\
\int_{S_{q}} b_{2}^{m, k}(t) c^{m, k}(t) d t & =2^{-1} k^{-1} T \quad \text { for } \quad q=1,2, \ldots, k .
\end{aligned}
$$

Using (3.1) and (3.3) we find

$$
\begin{aligned}
& F_{i, 1}^{m, n}\left(x, t_{q}, b_{1}^{n, k}(t)\right)=c^{n, k}(t) F_{i, 1}^{m, n}\left(x, t_{q}, 1\right)+\left(1-c^{n, k}(t)\right) F_{i, 1}^{m, n}\left(x, t_{q}, 0\right), \\
& F_{i, 2}^{m, n}\left(x, t_{q}, b_{2}^{n, k}(t)\right)=F_{i, 2}^{m, n}\left(x, t_{q}, 1\right)
\end{aligned}
$$

for almost all $t \in[0, T]$. From (3.9)-(3.10) we get

$$
\begin{gathered}
\int_{S_{q}} b_{1}^{m, k}(t)\left(G_{1}^{m}\left(x, t_{q}\right)+\sum_{j=1}^{2} \sum_{n=1}^{M} F_{1, j}^{m, n}\left(x, t_{q}, b_{j}^{n, k}(t)\right)\right) d t=0, \\
\int_{S_{q}} b_{2}^{m, k}(t)\left(G_{2}^{m}\left(x, t_{q}\right)+\sum_{j=1}^{2} \sum_{n=1}^{M} F_{2, j}^{m, n}\left(x, t_{q}, b_{j}^{n, k}(t)\right)\right) d t \\
=2^{-1} k^{-1} T\left(F_{2,1}^{m, m}\left(x, t_{q}, 1\right)-F_{2,1}^{m, m}\left(x, t_{q}, 0\right)\right) .
\end{gathered}
$$

Using (3.2), (3.7), (3.8), (3.4), $\left|b_{i}^{m, k}\right| \leqq 1$ and (3.5) we find

$$
\begin{aligned}
&\left|H_{i}^{m, k}(x, s)-\sum_{q=1}^{Q} \int_{S_{q}} b_{i}^{m, k}(t)\left(G_{i}^{m}\left(x, t_{q}\right)+\sum_{j=1}^{2} \sum_{n=1}^{M} F_{i, j}^{m, n}\left(x, t_{q}, b_{j}^{n, k}(t)\right)\right) d t\right| \\
& \leqq\left|H_{i}^{m, k}(x, s)-H_{i}^{m, k}\left(x, t_{Q}\right)\right| \\
&+\left|H_{i}^{m, k}\left(x, t_{Q}\right)-\int_{0}^{t_{Q}} b_{i}^{m, k}(t)\left(G_{i}^{m}(x, t)+\sum_{j=1}^{2} \sum_{n=1}^{M} F_{i, j}^{m, n}\left(x, t, b_{j}^{n, k}(t)\right)\right) d t\right| \\
&+\mid \int_{0}^{t_{Q}} b_{i}^{m, k}(t)\left(G_{i}^{m}(x, t)+\sum_{j=1}^{2} \sum_{n=1}^{M} F_{i, j}^{m, n}\left(x, t, b_{j}^{n, k}(t)\right)\right) d t \\
& \quad-\sum_{q=1}^{Q} \int_{S_{q}} b_{i}^{m, k}(t)\left(G_{i}^{m}\left(x, t_{q}\right)+\sum_{j=1}^{2} \sum_{n=1}^{M} F_{i, j}^{m, n}\left(x, t_{q}, b_{j}^{n, k}(t)\right)\right) d t \mid \\
& \leqq(2 M+1) N\left(k^{-1} T\right)+2(2 M+1) N k^{-1}+(2 M+1) \varepsilon(k) T \\
&=(2 M+1)\left(N k^{-1} T+2 N k^{-1}+\varepsilon(k) T\right) .
\end{aligned}
$$

Similarly, we can use (3.2), (3.7), (3.8), (3.5) to obtain

$$
\left|H_{2}^{m}(x, s)-\sum_{q=1}^{Q} 2^{-1} k^{-1} T\left(F_{2,1}^{m, m}\left(x, t_{q}, 1\right)-F_{2,1}^{m, m}\left(x, t_{q}, 0\right)\right)\right| \leqq\left|H_{2}^{m}(x, s)-H_{2}^{m}\left(x, t_{Q}\right)\right|
$$




$$
\begin{aligned}
& +\left|H_{2}^{m}\left(x, t_{Q}\right)-\sum_{q=1}^{Q} 2^{-1} k^{-1} T\left(F_{2,1}^{m, m}\left(x, t_{q}, 1\right)-F_{2,1}^{m, m}\left(x, t_{q}, 0\right)\right)\right| \\
\leqq & N k^{-1} T+\varepsilon(k) T .
\end{aligned}
$$

Now (3.11)-(3.13) give us

$$
\begin{aligned}
\left|H_{1}^{m, k}(x, s)\right| & \leqq(2 M+1)\left(N k^{-1} T+2 N k^{-1}+\varepsilon(k) T\right), \\
\left|H_{2}^{m, k}(x, s)-H_{2}^{m}(x, s)\right| & \leqq(2 M+1)\left(N k^{-1} T+2 N k^{-1}+\varepsilon(k) T\right)+N k^{-1} T+\varepsilon(k) T .
\end{aligned}
$$

The conclusion follows from the above, (3.2) and (3.6).

Lemma 3.2 Suppose that $v, \xi, T, \delta, M, C_{i}^{m}, h_{i}^{m}, v_{i}^{m}, g_{i}^{m}$ satisfy (3.14)-(3.24):

$v, \xi, T, \delta, M$ are positive, $M$ is an integer, $m \in\{1,2, \ldots, M\}, i \in\{1,2\}$,

$C_{i}^{m} \subset P, C_{i}^{m}$ is compact, the sets $C_{i}^{m}$ are disjoint,

$h_{i}^{m}: P \times(-\delta, T+\delta) \rightarrow R$ is $C^{\infty}, \quad v_{i}^{m} \in C_{c}^{\infty}\left(P, R^{2}\right), \quad g_{i}^{m} \in C_{c}^{\infty}(P, R)$,

if $x \notin C_{i}^{m}$ then $h_{i}^{m}(x, t)=0$,

$h_{i}^{m} \geqq 0, \quad$ if $x \in \operatorname{spt}\left(g_{i}^{m}\right)$, then $h_{i}^{m}(x, t)>\left|v_{i}^{m}(x)\right|$,

$0 \leqq g_{i}^{m} \leqq 1, \quad \operatorname{spt}\left(v_{i}^{m}\right) \subset\left\{x: g_{i}^{m}(x)=1\right\}$,

$$
x_{2} \frac{\partial}{\partial x_{1}} v_{i 1}^{m}\left(x_{1}, x_{2}\right)+x_{2} \frac{\partial}{\partial x_{2}} v_{i 2}^{m}\left(x_{1}, x_{2}\right)+v_{i 2}^{m}\left(x_{1}, x_{2}\right)=0,
$$

where $v_{i}^{m}=\left(v_{i 1}^{m}, v_{i 2}^{m}\right)$,

$$
\begin{aligned}
& \left(h_{1}^{m}(x, s)\right)^{2}=\left(h_{1}^{m}(x, 0)\right)^{2}-2 s \delta g_{1}^{m}(x) \\
& \left(h_{2}^{m}(x, s)\right)^{2}=\left(h_{2}^{m}(x, 0)\right)^{2}-2 s \delta g_{2}^{m}(x)-\int_{0}^{s} v_{2}^{m}(x) \cdot \nabla\left(p\left[v_{1}^{m}, h_{1, t}^{m}\right]-p\left[0, h_{1, t}^{m}\right]\right)(x) d t
\end{aligned}
$$

where $h_{i, t}^{m}(x)=h_{i}^{m}(x, t)$,

$$
L\left(h_{i, t}^{m}\right)(x) \geqq 0 \quad \text { if } \quad g_{i}^{m}(x)<1,
$$

$v u\left[a v_{i}^{m}, h_{i, t}^{m}\right](x) \cdot \Delta\left(u\left[a v_{i}^{m}, h_{i, t}^{m}\right]\right)(x) \geqq-\delta / 4 \quad$ if $|a| \leqq 1$ and $t \in[0, T] . \quad$ (3.24) Then there exist $\eta>0$ and $C^{\infty}$ functions $u: R^{3} \times(-\eta, T+\eta) \rightarrow R^{3}$ and $p: R^{3} \times$ $(-\eta, T+\eta) \rightarrow R$ satisfying (3.25)-(3.30):

$$
\begin{gathered}
u\left(x_{1}, x_{2}, x_{3}, t\right)=0 \quad \text { if }\left(x_{1},\left(x_{2}^{2}+x_{3}^{2}\right)^{1 / 2}\right) \notin \bigcup_{i=1}^{2} \bigcup_{m=1}^{M} C_{i}^{m}, \\
\sum_{i=1}^{3} \frac{\partial u_{i}}{\partial x_{i}}=0 \\
p(x, t)=\int_{R^{3}} \sum_{i=1}^{3} \sum_{j=1}^{3} \frac{\partial u_{j}}{\partial x_{i}}(y, t) \frac{\partial u_{i}}{\partial x_{j}}(y, t)(4 \pi|x-y|)^{-1} d y
\end{gathered}
$$




$$
\frac{\partial}{\partial t} 2^{-1}|u(x, t)|^{2} \leqq-u(x, t) \cdot \nabla\left(2^{-1}|u|^{2}+p\right)(x, t)+v u(x, t) \cdot \Delta u(x, t) \quad \text { if } \quad t \in[0, T]
$$

$$
\begin{gathered}
\left|u\left(x_{1}, x_{2}, x_{3}, 0\right)\right|=\sum_{m=1}^{M}\left(h_{1}^{m}+h_{2}^{m}\right)\left(x_{1},\left(x_{2}^{2}+x_{3}^{2}\right)^{1 / 2}, 0\right) \text { if }\left(x_{2}, x_{3}\right) \neq(0,0) \\
|| u\left(x_{1}, x_{2}, x_{3}, t\right)\left|-\sum_{m=1}^{M}\left(h_{1}^{m}+h_{2}^{m}\right)\left(x_{1},\left(x_{2}^{2}+x_{3}^{2}\right)^{1 / 2}, t\right)\right| \leqq \xi
\end{gathered}
$$

if $t \in[0, T]$ and $\left(x_{2}, x_{3}\right) \neq(0,0)$.

Proof. Assumptions (3.19), (3.18), (3.17), (3.15) imply

$$
\operatorname{spt}\left(v_{i}^{m}\right) \subset\left\{x: g_{i}^{m}(x)=1\right\} \subset \operatorname{spt}\left(g_{i}^{m}\right) \subset \operatorname{spt}\left(h_{i, t}^{m}\right) \subset C_{i}^{m} .
$$

Let $Q_{i}^{m, k}: P \times(-\delta, T+\delta) \rightarrow R$ be defined for $k=1,2,3, \ldots$ by the equation

$$
\begin{gathered}
Q_{i}^{m, k}(x, s)-2^{-1}\left(h_{i}^{m}(x, 0)\right)^{2}+s \delta g_{i}^{m}(x) \\
=-\int_{0}^{s} a_{i}^{m, k}(t) v_{i}^{m}(x) \cdot \nabla\left(2^{-1}\left(h_{i, t}^{m}\right)^{2}\right. \\
\left.\quad+\sum_{j=1}^{2} \sum_{n=1}^{M} p\left[a_{j}^{n, k}(t) v_{j}^{n}, h_{j, t}^{n}\right]\right)(x) d t,
\end{gathered}
$$

where the $a_{i}^{m, k}$ are the functions that were found in Lemma 3.1. Observe that the properties $\left|a_{i}^{m, k}\right| \leqq 1$, (3.18), (3.31), (3.15), (3.16) imply that this definition makes sense. Using Lemma 3.1, Lemma 2.1, (3.15), (3.16), (3.18) and (3.31) with

$$
G_{i}^{m}(x, t)=v_{i}^{m}(x) \cdot \nabla\left(2^{-1}\left(h_{i, t}^{m}\right)^{2}\right)(x), \quad F_{i, j}^{m, n}(x, t, a)=v_{i}^{m}(x) \cdot \nabla\left(p\left[a v_{j}^{n}, h_{j, t}^{n}\right]\right)(x),
$$

we discover that, when we restrict $(x, s)$ to $P \times[0, T]$, we have

$$
\begin{aligned}
& Q_{1}^{m, k}(x, s)-2^{-1}\left(h_{1}^{m}(x, 0)\right)^{2}+s \delta g_{1}^{m}(x) \text { converges uniformly to } 0, \\
& Q_{2}^{m, k}(x, s)-2^{-1}\left(h_{2}^{m}(x, 0)\right)^{2}+s \delta g_{2}^{m}(x) \text { converges uniformly to } \\
& \quad-\int_{0}^{s} 2^{-1} v_{2}^{m}(x) \cdot \nabla\left(p\left[v_{1}^{m}, h_{1, t}^{m}\right]-p\left[0, h_{1, t}^{m}\right]\right)(x) d t
\end{aligned}
$$

as $k$ goes to $\infty$. Combining this with (3.21), (3.22), we find

$$
Q_{i}^{m, k} \rightarrow 2^{-1}\left(h_{i}^{m}\right)^{2} \quad \text { uniformly on } P \times[0, T] \text { as } k \rightarrow \infty .
$$

Using (3.33), (3.18), (3.16), we find $\varepsilon>0$ and an integer $k_{0}$ satisfying

$$
Q_{i}^{m, k}(x, s) \geqq 2^{-1}\left(\left|v_{i}^{m}(x)\right|+\varepsilon\right)^{2} \quad \text { if } \quad k \geqq k_{0}, \quad x \in \operatorname{spt}\left(g_{i}^{m}\right), \quad s \in[0, T] .
$$

From (3.32), (3.21), (3.22) we conclude

$$
Q_{i}^{m, k}(x, s)=2^{-1}\left(h_{i}^{m}(x, s)\right)^{2} \quad \text { if } \quad x \notin \operatorname{spt}\left(v_{i}^{m}\right) .
$$

We pause for an informal discussion. We will have to deal with the square root of $2 Q_{i}^{m, k}$ for $k \geqq k_{0}$. This square root will be called $q_{i}^{m, k}$. In order to verify that $q_{i}^{m, k}$ is defined and that it satisfies the right properties, we will use (3.19) to write $P$ in 
the form

$$
P=\left(P \sim \operatorname{spt}\left(v_{i}^{m}\right)\right) \cup\left\{x: g_{i}^{m}(x)>0\right\} \equiv V_{1} \cup V_{2},
$$

and note the following: If $x \in P \sim \operatorname{spt}\left(v_{i}^{m}\right)$, then (3.35), (3.18) imply $q_{i}^{m, k}(x, t)=h_{i}^{m}(x, t)$. If $x \in \operatorname{spt}\left(g_{i}^{m}\right)$, then (3.34) implies $q_{i}^{m, k}(x, t) \geqq\left|v_{i}^{m}(x)\right|+\varepsilon$ for $t \in[0, T]$ and $k \geqq k_{0}$. In the first case, properties of $q_{i}^{m, k}$ will follow from corresponding properties of $h_{i}^{m}$. In the second case, we can use the boundedness of $q_{i}^{m, k}$ away from zero (and away from $\left.\left|v_{i}^{m}\right|\right)$, the compactness of $\operatorname{spt}\left(g_{i}^{m}\right)$ and properties of $Q_{i}^{m, k}$ to obtain results for $q_{i}^{m, k}$. This type of argument will be used repeatedly. It will be called the $V_{1}-V_{2}$ argument.

The precise statement of all this is the following: There exist $\delta_{k}>0$ and $q_{i}^{m, k}$ for $k \geqq k_{0}$ satisfying (3.36)-(3.39):

$$
\begin{aligned}
& q_{i}^{m, k}: P \times\left(-\delta_{k}, T+\delta_{k}\right) \rightarrow R \quad \text { is a } C^{\infty} \text { function, } \\
& q_{i}^{m, k} \geqq 0, \quad Q_{i}^{m, k}(x, s)=2^{-1}\left(q_{i}^{m, k}(x, s)\right)^{2} \quad \text { if } \quad s \in\left(-\delta_{k}, T+\delta_{k}\right), \\
& q_{i}^{m, k}(x, s)=h_{i}^{m}(x, s) \quad \text { if } \quad x \notin \operatorname{spt}\left(v_{i}^{m}\right) \quad \text { and } \quad s \in\left(-\delta_{k}, T+\delta_{k}\right), \\
& q_{i}^{m, k}(x, s) \geqq\left|v_{i}^{m}(x)\right|+\varepsilon \quad \text { if } \quad x \in \operatorname{spt}\left(g_{i}^{m}\right) \quad \text { and } \quad s \in\left(-\delta_{k}, T+\delta_{k}\right) .
\end{aligned}
$$

Using (3.17), (3.31), (3.38) we get

$$
q_{i}^{m, k}(x, s)=0 \quad \text { if } \quad x \notin C_{i}^{m} .
$$

The $V_{1}-V_{2}$ argument and (3.33) yield

$$
q_{i}^{m, k} \rightarrow h_{i}^{m} \quad \text { uniformly on } P \times[0, T] \text { as } k \rightarrow \infty .
$$

The $V_{1}-V_{2}$ argument and (3.32), (3.31), (3.15), (3.16), (3.18) yield $N<\infty$ satisfying

$$
\begin{aligned}
\left|\frac{\partial}{\partial x_{j}} q_{i}^{m, k}(x, s)\right| & \leqq N, \quad\left|\frac{\partial^{2}}{\partial x_{j} \partial x_{n}} q_{i}^{m, k}(x, s)\right| \leqq N, \\
\left|\frac{\partial^{3}}{\partial x_{j} \partial x_{n} \partial x_{r}} q_{i}^{m, k}(x, s)\right| & \leqq N \quad \text { if } \quad s \in[0, T] .
\end{aligned}
$$

The mean value theorem and (3.41), (3.42), (3.15)-(3.17) give us

$$
\begin{aligned}
& \frac{\partial}{\partial x_{j}} q_{i}^{m, k} \rightarrow \frac{\partial}{\partial x_{j}} h_{i}^{m} \text { and } \frac{\partial^{2}}{\partial x_{j} \partial x_{n}} q_{i}^{m, k} \rightarrow \frac{\partial^{2}}{\partial x_{j} \partial x_{n}} h_{i}^{m} \\
& \text { uniformly on } P \times[0, T] \text { as } k \rightarrow \infty .
\end{aligned}
$$

From (3.32) and (3.37) we get

$$
\begin{aligned}
\frac{\partial}{\partial t} 2^{-1}\left(q_{i}^{m, k}(x, t)\right)^{2}= & -\delta g_{i}^{m}(x)-a_{i}^{m, k}(t) v_{i}^{m}(x) \cdot \nabla\left(2^{-1}\left(h_{i, t}^{m}\right)^{2}\right. \\
& \left.+\sum_{j=1}^{2} \sum_{n=1}^{M} p\left[a_{j}^{n, k}(t) v_{j}^{n}, h_{j, t}^{n}\right]\right)(x)
\end{aligned}
$$

for $-\delta_{k}<t<T+\delta_{k}$. Using (3.36), (3.37), (3.40), (3.15), (3.16), (3.39), (3.19) and 
$\left|a_{i}^{m, k}\right| \leqq 1$, we conclude

$$
p^{*}\left[a_{i}^{m, k}(t) v_{i}^{m}, q_{i, t}^{m, k}\right], p\left[a_{i}^{m, k}(t) v_{i}^{m}, q_{i, t}^{m, k}\right], u\left[a_{i}^{m, k}(t) v_{i}^{m}, q_{i, t}^{m, k}\right] \quad \text { make sense. }
$$

Now we will show the existence of $k_{1} \geqq k_{0}$ satisfying

$$
\begin{aligned}
\frac{\partial}{\partial t} 2^{-1}\left(q_{i}^{m, k}(x, t)\right)^{2} \leqq & -(\delta / 2) g_{i}^{m}(x)-a_{i}^{m, k}(t) v_{i}^{m}(x) \cdot \nabla\left(2^{-1}\left(q_{i, t}^{m, k}\right)^{2}\right. \\
& \left.+\sum_{j=1}^{2} \sum_{n=1}^{M} p\left[a_{j}^{n, k}(t) v_{j}^{n}, q_{j, t}^{n, k}\right]\right)(x) \\
& \text { if } \quad k \geqq k_{1} \quad \text { and } \quad(x, t) \in P \times[0, T] .
\end{aligned}
$$

If $x \notin \operatorname{spt}\left(v_{i}^{m}\right)$, then the long terms of (3.44) and (3.46) are zero. Thus, (3.46) follows in this case from (3.44), (3.45) and $(\delta / 2) g_{i}^{m} \geqq 0$ (see (3.14), (3.19)). If we restrict our attention to $x \in \operatorname{spt}\left(v_{i}^{m}\right)$ then (3.45), $\left|a_{i}^{m, k}\right| \leqq 1,(3.41),(3.43),(3.38),(3.39),(3.16),(3.19)$ gives us $k_{1} \geqq k_{0}$ satisfying

$$
\begin{aligned}
& \mid a_{i}^{m, k}(t) v_{i}^{m}(x) \cdot \nabla\left(2^{-1}\left(q_{i, t}^{m, k}\right)^{2}+\sum_{j=1}^{2} \sum_{n=1}^{M} p\left[a_{j}^{n, k}(t) v_{j}^{n}, q_{j, t}^{n, k}\right]\right)(x) \\
& \quad-a_{i}^{m, k}(t) v_{i}^{m}(x) \cdot \nabla\left(2^{-1}\left(h_{i, t}^{m}\right)^{2}+\sum_{j=1}^{2} \sum_{n=1}^{M} p\left[a_{j}^{n, k}(t) v_{j}^{n}, h_{j, t}^{n}\right]\right)(x) \mid \\
& \leqq \delta / 2=(\delta / 2) g_{i}^{m}(x)
\end{aligned}
$$

if $k \geqq k_{1}, x \in \operatorname{spt}\left(v_{i}^{m}\right)$ and $t \in[0, T]$. Consequently, (3.46) follows from (3.44) in this case also. We use (3.45) to define

$$
\begin{aligned}
& u^{k}(x, t)=\sum_{i=1}^{2} \sum_{m=1}^{M} u\left[a_{i}^{m, k}(t) v_{i}^{m}, q_{i, t}^{m, k}\right](x), \\
& p^{k}(x, t)=\sum_{i=1}^{2} \sum_{m=1}^{M} p^{*}\left[a_{i}^{m, k}(t) v_{i}^{m}, q_{i, t}^{m, k}\right](x) \text { for } k \geqq k_{1} \text { and } x \in R^{3} .
\end{aligned}
$$

Using (3.47), (3.40), (3.15) and Lemma 2.2, we get

$$
p^{k}(x, t)=\int_{R^{3}} \sum_{i=1}^{3} \sum_{j=1}^{3} \frac{\partial u_{j}^{k}}{\partial x_{i}}(y, t) \frac{\partial u_{i}^{k}}{\partial x_{j}}(y, t)(4 \pi|x-y|)^{-1} d y .
$$

The general identity $\left|u[v, f]\left(x_{1}, x_{2}, 0\right)\right|=f\left(x_{1}, x_{2}\right)$, which is valid whenever $\left(x_{1}, x_{2}\right) \in P$ and $u[v, f]$ makes sense, and properties (3.47), (3.40), (3.15), (3.31) imply

$$
\begin{gathered}
\left|u^{k}\left(x_{1}, x_{2}, 0, t\right)\right|^{2}=\sum_{i=1}^{2} \sum_{m=1}^{M}\left(q_{i}^{m, k}\left(x_{1}, x_{2}, t\right)\right)^{2}, \\
v_{i}^{m}\left(x_{1}, x_{2}\right) \cdot \nabla\left(2^{-1}\left(q_{i, t}^{m, k}\right)^{2}\right)\left(x_{1}, x_{2}\right)=\sum_{r=1}^{2} v_{i r}^{m}\left(x_{1}, x_{2}\right) \frac{\partial}{\partial x_{r}}\left(2^{-1}\left|u^{k}\right|^{2}\right)\left(x_{1}, x_{2}, 0, t\right)
\end{gathered}
$$

if $k \geqq k_{1}$ and $\left(x_{1}, x_{2}\right) \in P$. If we also have $t \in[0, T]$, then we may apply (3.46), (3.47) and $\left(\partial / \partial x_{3}\right)\left(2^{-1}\left|u^{k}\right|^{2}+p^{k}\right)\left(x_{1}, x_{2}, 0, t\right)=0$ (which follows from the rotational sym- 
metry of $\left|u^{k}\right|^{2}$ and $p^{k}$ about the $x_{1}$ axis) to obtain the inequality

$$
\begin{gathered}
\frac{\partial}{\partial t} 2^{-1}\left|u^{k}\left(x_{1}, x_{2}, 0, t\right)\right|^{2}=\sum_{i=1}^{2} \sum_{m=1}^{M} \frac{\partial}{\partial t} 2^{-1}\left(q_{i}^{m, k}\left(x_{1}, x_{2}, t\right)\right)^{2} \\
\leqq-(\delta / 2)\left(\sum_{i=1}^{2} \sum_{m=1}^{M} g_{i}^{m}\left(x_{1}, x_{2}\right)\right) \\
-\sum_{i=1}^{2} \sum_{m=1}^{M} \sum_{r=1}^{2} a_{i}^{m, k}(t) v_{i r}^{m}\left(x_{1}, x_{2}\right) \frac{\partial}{\partial x_{r}}\left(2^{-1}\left|u^{k}\right|^{2}+p^{k}\right)\left(x_{1}, x_{2}, 0, t\right) \\
=-(\delta / 2)\left(\sum_{i=1}^{2} \sum_{m=1}^{M} g_{i}^{m}\left(x_{1}, x_{2}\right)\right) \\
-u^{k}\left(x_{1}, x_{2}, 0, t\right) \cdot \nabla\left(2^{-1}\left|u^{k}\right|^{2}+p^{k}\right)\left(x_{1}, x_{2}, 0, t\right)
\end{gathered}
$$

where the gradient in the last line is taken with respect to all three space variables. Rotational symmetry yields

$$
\begin{aligned}
& \frac{\partial}{\partial t} 2^{-1}\left|u^{k}(x, t)\right|^{2} \leqq-(\delta / 2)\left(\sum_{i=1}^{2} \sum_{m=1}^{M} g_{i}^{m}\left(x_{1},\left(x_{2}^{2}+x_{3}^{2}\right)^{1 / 2}\right)\right) \\
& -u^{k}(x, t) \cdot \nabla\left(2^{-1}\left|u^{k}\right|^{2}+p^{k}\right)(x, t) \\
& \quad \text { if } \quad k \geqq k_{1}, \quad x=\left(x_{1}, x_{2}, x_{3}\right), \quad\left(x_{2}, x_{3}\right) \neq(0,0) \text { and } t \in[0, T] .
\end{aligned}
$$

For $k \geqq k_{1}$ and $x \in R^{3}$ we will use the notation

$$
f_{i, t}^{m, k}(x) \equiv u\left[a_{i}^{m, k}(t) v_{i}^{m}, q_{i, t}^{m, k}\right](x) \cdot \Delta\left(u\left[a_{i}^{m, k}(t) v_{i}^{m}, q_{i, t}^{m, k}\right]\right)(x) .
$$

Using $\left|a_{i}^{m, k}\right| \leqq 1,(3.24),(3.41),(3.43)$, (3.38), (3.39), (3.31), (3.15), (3.16) we can prove the existence of an integer $k_{2} \geqq k_{1}$ satisfying

$$
v f_{i, t}^{m, k}(x) \geqq-\delta / 2 \quad \text { if } \quad t \in[0, T] \text { and } k \geqq k_{2} .
$$

If $\left(x_{1}, x_{2}\right) \in P$ and $g_{i}^{m}\left(x_{1}, x_{2}\right)<1$ then the consequence $\left(x_{1}, x_{2}\right) \notin \operatorname{spt}\left(v_{i}^{m}\right)$ (see (3.19)) and (3.50), (3.38), (3.18), (3.23), (3.14) yield

$$
\begin{aligned}
v f_{i, t}^{m, k}\left(x_{1}, x_{2}, 0\right) & =v u\left[0, h_{i, t}^{m}\right]\left(x_{1}, x_{2}, 0\right) \cdot \Delta\left(u\left[0, h_{i, t}^{m}\right]\right)\left(x_{1}, x_{2}, 0\right) \\
& =v h_{i, t}^{m}\left(x_{1}, x_{2}\right) L\left(h_{i, t}^{m}\right)\left(x_{1}, x_{2}\right) \geqq 0 .
\end{aligned}
$$

Combining this with the rotational symmetry of $f_{i, t}^{m, k}$ about the $x_{1}$ axis and (3.14), (3.19) we obtain

$$
\begin{aligned}
& v f_{i, t}^{m, k}\left(x_{1}, x_{2}, x_{3}\right) \geqq 0 \geqq-(\delta / 2) g_{i}^{m}\left(x_{1},\left(x_{2}^{2}+x_{3}^{2}\right)^{1 / 2}\right) \\
& \text { if }\left(x_{2}, x_{3}\right) \neq(0,0) \text { and } g_{i}^{m}\left(x_{1},\left(x_{2}^{2}+x_{3}^{2}\right)^{1 / 2}\right)<1 .
\end{aligned}
$$

Now (3.51), (3.52), (3.19) give us

$$
\begin{aligned}
& v f_{i, t}^{m, k}\left(x_{1}, x_{2}, x_{3}\right) \geqq-(\delta / 2) g_{i}^{m}\left(x_{1},\left(x_{2}^{2}+x_{3}^{2}\right)^{1 / 2}\right) \\
& \text { if } k \geqq k_{2},\left(x_{2}, x_{3}\right) \neq(0,0) \text { and } t \in[0, T] .
\end{aligned}
$$


Using (3.53), (3.50), (3.47), (3.40), (3.15) we find

$$
\begin{aligned}
& v u^{k}(x, t) \cdot \Delta u^{k}(x, t) \geqq-(\delta / 2)\left(\sum_{i=1}^{2} \sum_{m=1}^{M} g_{i}^{m}\left(x_{1},\left(x_{2}^{2}+x_{3}^{2}\right)^{1 / 2}\right)\right) \\
& \text { if } k \geqq k_{2}, \quad\left(x_{2}, x_{3}\right) \neq(0,0) \quad \text { and } \quad t \in[0, T] .
\end{aligned}
$$

Finally, we show that the conclusions of Lemma 3.2 are satisfied when $\eta=\delta_{k}, u=u^{k}$, $p=p^{k}$ and $k$ is sufficiently large. We have that (3.40), (3.47) imply (3.25); (3.20) implies (3.26); (3.48) implies (3.27); (3.49), (3.54) and $u\left(x_{1}, 0,0, t\right)=0$ imply (3.28); (3.15), (3.40), (3.37), (3.32), (3.18) imply (3.29); (3.15), (3.40), (3.41) imply (3.30).

\section{Section 4. The Geometric Building Blocks}

To begin with, we use Lemma 6.2 of [4]. This lemma says that we can construct $U, K, f, z, F, A, B, C, D$ such that (4.1)-(4.10) are satisfied:

$$
\begin{aligned}
& U=\left\{\left(x_{1}, x_{2}\right) \in R^{2}:\left|x_{1}\right|<1,1 / 8<x_{2}<7 / 8\right\}, \\
& f \in C_{c}^{\infty}(P, R), \quad z=\left(z_{1}, z_{2}\right) \in C_{c}^{\infty}\left(P, R^{2}\right), \quad F=\left(F_{1}, F_{2}\right) \in C^{\infty}\left(R^{2}, R^{2}\right), \\
& K \text { is compact, spt }(z) \subset K \subset U, \\
& f \geqq 0, \quad f(x)=0 \text { if } \quad x \notin U, \quad f(x)>|z(x)| \text { if } \quad x \in U, \\
& L(f)(x) \geqq 0 \text { if } \quad x \notin K, \quad L(f)(x)>0 \quad \text { if } \quad x \in U \sim K, \\
& x_{2} \frac{\partial z_{1}}{\partial x_{1}}\left(x_{1}, x_{2}\right)+x_{2} \frac{\partial z_{2}}{\partial x_{2}}\left(x_{1}, x_{2}\right)+z_{2}\left(x_{1}, x_{2}\right)=0 . \\
& \nabla(p[0, f]-p[z, f])(x)=F(x) \text { if } \quad x \in P, \\
& A, B, C, D \text { are real numbers, } B>0, \quad C>0, \quad D>0, \\
& F_{1}(A, 0)=B, \text { if } \quad x \in R, \quad \text { then }\left|F_{1}(x, 0)\right| \leqq B \quad \text { and } \quad F_{2}(x, 0)=0, \\
& \lim _{x \rightarrow \infty} x^{4} F_{1}(x, 0)=D, \text { if } x \in R^{2}, \quad \text { then }|F(x)| \leqq C|x|^{-4} \quad \text { and } \\
& \qquad|\nabla F(x)| \leqq C|x|^{-5} .
\end{aligned}
$$

We will use the following definitions:

$$
\begin{aligned}
F^{\alpha, \rho, \sigma}\left(x_{1}, x_{2}\right) & =\left(\sigma^{2} / \rho\right) F\left(\left(x_{1}-\alpha\right) / \rho, x_{2} / \rho\right), \\
f^{\alpha, \rho, \sigma}\left(x_{1}, x_{2}\right) & =\sigma f\left(\left(x_{1}-\alpha\right) / \rho, x_{2} / \rho\right), \\
z^{\alpha, \rho, \sigma}\left(x_{1}, x_{2}\right) & =\sigma z\left(\left(x_{1}-\alpha\right) / \rho, x_{2} / \rho\right), \\
U^{\alpha, \rho} & =\left\{x \in R^{2}:\left(\left(x_{1}-\alpha\right) / \rho, x_{2} / \rho\right) \in U\right\}, \\
K^{\alpha, \rho} & =\left\{x \in R^{2}:\left(\left(x_{1}-\alpha\right) / \rho, x_{2} / \rho\right) \in K\right\}
\end{aligned}
$$

if $\alpha \in R, \rho>0, \sigma>0$. With the aid of (4.4), (4.7), we conclude:

$$
\begin{aligned}
& \operatorname{spt}(f)=\operatorname{closure}(U), \operatorname{spt}\left(f^{\alpha, \rho, \sigma}\right)=\operatorname{closure}\left(U^{\alpha, \rho}\right), \\
& \nabla\left(p\left[0, f^{\alpha, \rho, \sigma}\right]-p\left[z^{\alpha, \rho, \sigma}, f^{\alpha, \rho, \sigma}\right]\right)(x)=F^{\alpha, \rho, \sigma}(x) \text { if } \quad x \in P .
\end{aligned}
$$


Properties (4.2), (4.8), (4.9), (4.10) say that all of the hypotheses of Sect. 4 of [4] are satisfied. In what follows, we will use some results of that section (where, of course, the definition of $f^{\alpha, \rho, \sigma}$ is the same as in (4.11)).

Lemma. 4.1. There exist real numbers $a^{\prime}, a^{\prime \prime}, r^{\prime}, r^{\prime \prime}, s^{\prime}, s^{\prime \prime}, E$ such that conditions (4.14)-(4.17) hold:

$$
0<E<r^{\prime \prime} / 8, \quad r^{\prime \prime}<r^{\prime} / 8, \quad r^{\prime}<1 / 8, \quad a^{\prime}=A-r^{\prime} A, \quad a^{\prime \prime}=A-r^{\prime \prime} A,
$$

if $x_{1} \in R$ and $\left|x_{2}\right| \leqq E$, then

$$
\left(F_{1}^{a^{\prime}, r^{\prime}, s^{\prime}}+F_{1}^{a^{\prime \prime}, r^{\prime \prime}, s^{\prime \prime}}+F_{1}\right)\left(x_{1}, x_{2}\right)>-(1.01) B
$$

if $\left|x_{1}-A\right| \leqq\left(10^{4} C / D\right) E$ and $\left|x_{2}\right| \leqq E$, then

$$
\left(F_{1}^{a^{\prime}, r^{\prime}, s^{\prime}}+F_{1}^{a^{\prime \prime}, r^{\prime \prime}, s^{\prime \prime}}+F_{1}\right)\left(x_{1}, x_{2}\right) \geqq(6.99) B,
$$

if $x \in R^{2}$ and $|x|>2|A|$, then

$$
\left|\left(F^{a^{\prime}, r^{\prime}, s^{\prime}}+F^{a^{\prime \prime}, r^{\prime \prime}, s^{\prime \prime}}+F\right)(x)\right| \leqq 2 C|x|^{-4} .
$$

Proof. This is the initial step of the construction carried out in Sect. 4 of [4]. We use (4.8), (4.10), (4.11), (4.12), (4.13) and Lemma 4.4 of that paper.

Lemma 4.2. There exists $M<\infty$ with the following property: If $m \geqq M,\left|x_{1}-m\right| \leqq$ $10^{4} C / D$ and $\left|x_{2}\right| \leqq 1$, then $\left|F_{1}\left(x_{1}, x_{2}\right)-m^{-4} D\right| \leqq 10^{-3} m^{-4} D$.

Proof. This is done in (4.14)-(4.17) of [4].

Now we introduce a constant $X$ that was not used in [4]. Let $X$ satisfy

$X>2, \quad X>4|A|, \quad X>4\left(10^{4} C / D\right) E, \quad 2 C X^{-4}\left(\sum_{n=-\infty}^{\infty}|| n|-1 / 2|^{-4}\right)<(.005) B$.

In (4.18)-(4.21) of [4] we choose $\varepsilon$ small enough to satisfy

$$
\begin{gathered}
\varepsilon^{-1}\left(1+\varepsilon^{2}\right)^{1 / 2} E / 10>2|A|+1, \quad 2 C\left(\varepsilon^{-1}\left(1+\varepsilon^{2}\right)^{1 / 2} E / 10\right)^{-4}<10^{-3} \varepsilon^{2} B, \quad \\
0<\varepsilon<.01, \quad \varepsilon^{-1} 10^{3} C / D>M, \quad \varepsilon^{-1} 10^{2} C / D>10^{4} C / D, \quad(.99)\left(1+\varepsilon^{2}\right)^{1 / 2}<1,
\end{gathered}
$$

and we defined $a, r, s, d$ as follows:

$$
\begin{aligned}
& r=\varepsilon^{-1}\left(1+\varepsilon^{2}\right)^{1 / 2} E, \quad a=-r\left(\varepsilon^{-1} 10^{3} C / D\right), \\
& d=r\left(10^{4} C / D\right), \quad s=\left[((1.02) B /(.999))\left(\varepsilon^{-1} 10^{3} C / D\right)^{4}(r / D)\right]^{1 / 2} .
\end{aligned}
$$

At this point, we come to a sharpening of the construction of [4]. Recalling that $\zeta<1$ is the given number of Sect. 1, we see that $\varepsilon$ can be chosen so that (4.22)-(4.24) are also satisfied:

$$
\begin{gathered}
\varepsilon^{-1}\left(1+\varepsilon^{2}\right)^{1 / 2} E\left(10^{3} C / D\right) /(4 X) \text { is a positive integer, } \\
((.48) \varepsilon)^{5}\left(\varepsilon^{-1}\left(1+\varepsilon^{2}\right)^{1 / 2} E\left(10^{3} C / D\right) /(4 X)+1\right)>1, \\
20 C\left(\varepsilon^{-1}\left(1+\varepsilon^{2}\right)^{1 / 2} E\left(10^{3} C / D\right) /(4 X)+1\right)\left(\varepsilon^{-1}\left(1+\varepsilon^{2}\right)^{1 / 2} E / 10\right)^{-4} \leqq 10^{-3} \varepsilon^{2} B .
\end{gathered}
$$


Lemma. 4.3. If $-d \leqq x_{1} \leqq d$ and $0 \leqq x_{2} \leqq r$, then

$$
\left|F_{2}^{a, r, s}\left(x_{1}, x_{2}\right)\right| \leqq(.002) B \varepsilon \text { and }(1.02) B \leqq F_{1}^{a, r, s}\left(x_{1}, x_{2}\right) \leqq(1.03) B \text {. }
$$

Proof. This is Lemma 4.5 of [4].

Lemma 4.4. There exists $v_{2}=\left(v_{21}, v_{22}\right) \in C_{c}^{\infty}\left(P, R^{2}\right)$ that satisfies the six properties listed below:

$$
\begin{aligned}
& \operatorname{spt}\left(v_{2}\right) \subset(-d, d) \times\left(10^{-3} \varepsilon r, r\right), \\
& \operatorname{spt}\left(v_{2}\right) \text { and }[r-d, d-r] \times[E, r / 10] \quad \text { are disjoint, } \\
& x_{2} \frac{\partial}{\partial x_{1}} v_{21}\left(x_{1}, x_{2}\right)+x_{2} \frac{\partial}{\partial x_{2}} v_{22}\left(x_{1}, x_{2}\right)+v_{22}\left(x_{1}, x_{2}\right)=0, \\
& \left|v_{2}(x)\right| \leqq 1, \quad v_{21}(x) \geqq-\varepsilon^{2}, \quad\left|v_{22}(x)\right| \leqq \varepsilon / 2, \\
& \text { if }\left|x_{1}\right| \leqq d-r \quad \text { and }(.02) \varepsilon r \leqq x_{2} \leqq(.98) \varepsilon r, \quad \text { then } v_{2}\left(x_{1}, x_{2}\right)=(1,0), \\
& \text { if }\left|x_{1}\right| \leqq d-r \quad \text { and } 0<x_{2}<E, \text { then } v_{21}\left(x_{1}, x_{2}\right) \geqq 0 \\
& \text { and } v_{22}\left(x_{1}, x_{2}\right)=0 .
\end{aligned}
$$

Proof. This is Lemma 4.8 and (4.40)-(4.43) of [4], where $v_{2}$ is called $w$. Note that the $\left(v_{1}, v_{2}\right)$ in $(4.40)$ of [4] has nothing to do with the $v_{2}$ here.

Now we make the definition

$$
\tau=(.48) \varepsilon, \quad Y=r\left(10^{3} C / D\right) /(4 X) .
$$

From (4.19)-(4.24) and (4.31) we obtain

$$
\begin{aligned}
& Y X=d / 40, \quad Y \text { is a positive integer, } \tau^{\zeta}(Y+1)>1, \quad 0<\tau<1, \\
& r / 10>2|A|+1, \quad 20 C(Y+1)(r / 10)^{-4} \leqq 10^{-3} \varepsilon^{2} B .
\end{aligned}
$$

Using (4.20), (4.21), (4.31) we find

$$
\text { (.99) } r \varepsilon<E<r / 100 \text {, hence } \tau d \leqq\left(10^{4} C / D\right) E \text {. }
$$

Also, (4.8), (4.10) and (4.21) yield

$$
C / D \geqq 1, \text { hence } d \geqq 10^{4} r .
$$

Lemma 4.5. The $2(Y+1)$ closed intervals

$$
\begin{array}{cc}
{[\tau(a-r)+A+n X, \quad \tau(a+r)+A+n X],} & n=0,1, \ldots, Y \text { and } \\
{\left[-\tau d+A+n^{\prime} X, \quad \tau d+A+n^{\prime} X\right],} & n^{\prime}=0,1, \ldots, Y
\end{array}
$$

are pairwise disjoint. Furthermore, all of these intervals are contained in the open interval $(r-d, d-r)$.

Proof. All we have to show is

$$
\begin{aligned}
& 2 \tau r<X, \quad 2 \tau d<X, \\
& r-d<\tau(a-r)+A,
\end{aligned}
$$




$$
\begin{aligned}
& \tau(a+r)+A+Y X<-\tau d+A, \\
& \tau d+A+Y X<d-r .
\end{aligned}
$$

Inequality (4.40) says that the rightmost interval in (4.36) is to the left of the leftmost interval in (4.37). From (4.31), (4.21), (4.20), (4.18) we get

$$
2 \tau d=2(.48) \varepsilon\left(\varepsilon^{-1}\left(1+\varepsilon^{2}\right)^{1 / 2} E\right)\left(10^{4} C / D\right)<\left(10^{4} C / D\right) E<X .
$$

This fact and (4.35) imply (4.38). Now (4.33), (4.31), (4.20), (4.35), (4.21) imply

$$
\begin{gathered}
-A+(1+\tau) r-d<r / 20+r+(.48) r / 100-d<-(.999) d \\
=-(.999) r\left(10^{4} C / D\right)<(.48) \varepsilon\left(-r\left(\varepsilon^{-1} 10^{3} C / D\right)\right)=\tau a,
\end{gathered}
$$

which gives (4.39). Using (4.32), (4.21), (4.31), (4.20), (4.35) we get

$$
Y X=(1 / 4) r\left(10^{3} C / D\right)=\operatorname{\tau r}\left((1.92)^{-1} \varepsilon^{-1} 10^{3} C / D\right)<\tau r\left(\varepsilon^{-1} 10^{3} C / D-1-10^{4} C / D\right) .
$$

The above and (4.21) imply (4.40). Finally, (4.32), (4.35), (4.20), (4.31), (4.33) yield

$$
Y X=d / 40<d-r-r / 10-(.48) \varepsilon d<d-r-A-\tau d,
$$

which gives (4.41).

Lemma 4.6. The $3(Y+1)$ closed rectangles

$$
\begin{aligned}
& {[-1+n X, 1+n X] \times[1 / 8,7 / 8],} \\
& {\left[a^{\prime}-r^{\prime}+n^{\prime} X, a^{\prime}+r^{\prime}+n^{\prime} X\right] \times\left[r^{\prime} / 8,7 r^{\prime} / 8\right],} \\
& {\left[a^{\prime \prime}-r^{\prime \prime}+n^{\prime \prime} X, a^{\prime \prime}+r^{\prime \prime}+n^{\prime \prime} X\right] \times\left[r^{\prime \prime} / 8,7 r^{\prime \prime} / 8\right],}
\end{aligned}
$$

where $n, n^{\prime}, n^{\prime \prime} \in\{0,1, \ldots, Y\}$, are disjoint. In addition, all of these rectangles are contained in the open rectangle $(r-d, d-r) \times(E, r / 10)$. Finally, the intervals $[a-r, a+r]$ and $[-d, d]$ are disjoint.

Proof. From $2 r^{\prime \prime}<2 r^{\prime}<2<X$ (see (4.14), (4.18)) we conclude that each of (4.42)(4.44) consists of $Y+1$ disjoint rectangles. The inequalities $7 r^{\prime \prime} / 8<r^{\prime} / 8,7 r^{\prime} / 8<1 / 8$ (see (4.14)) imply that rectangles from different lines in (4.42)-(4.44) are disjoint. In order to prove the second assertion of the lemma, we observe that (4.14), (4.33), (4.35) imply

$$
\begin{aligned}
& \left|a^{\prime}\right|+r^{\prime}<|A|+1, \quad\left|a^{\prime \prime}\right|+r^{\prime \prime}<|A|+1, \\
& 1+d / 40 \leqq|A|+1+d / 40<r / 10+d / 40<d-r .
\end{aligned}
$$

These facts and (4.32) imply

$$
1+Y X<d-r, \quad\left|a^{\prime}\right|+r^{\prime}+Y X<d-r, \quad\left|a^{\prime \prime}\right|+r^{\prime \prime}+Y X<d-r .
$$

Therefore, the projections of the rectangles in (4.42)-(4.44) on the $x_{1}$ axis are contained in $(r-d, d-r)$. The second assertion follows from this fact, (4.14) and (4.33). Since (4.20), (4.21), (4.35) imply

$$
a+r=-r\left(\varepsilon^{-1} 10^{3} C / D\right)+r<-10 r\left(10^{4} C / D\right)+r=-10 d+r<-d,
$$

we obtain the third assertion of the lemma. 
We set

$$
F^{*}=F^{a^{\prime}, r^{\prime}, s^{\prime}}+F^{a^{\prime \prime}, r^{\prime \prime}, s^{\prime \prime}}+F .
$$

Lemma 4.7. If $\left(x_{1}, x_{2}\right) \in R^{2}$ and $j \in\{0,1, \ldots, Y\}$ satisfies the condition

$$
\left|x_{1}-j X\right|=\min \left\{\left|x_{1}-n X\right|: n=0,1, \ldots, Y\right\},
$$

then we have $\sum_{\substack{n=0 \\ n \neq j}}^{Y}\left|F^{*}\left(x_{1}-n X, x_{2}\right)\right| \leqq(.005) B$.

Proof. If $n \neq j$, then $\left|x_{1}-n X\right| \geqq(|n-j|-1 / 2) X$. The conclusion follows from (4.45), (4.17) and the second and fourth inequalities of (4.18).

Lemma 4.8. If $\left(x_{1}, x_{2}\right) \in R^{2}$ and $\left|x_{2}\right| \leqq E$, then $\sum_{n=0}^{Y} F_{1}^{*}\left(x_{1}-n X, x_{2}\right)>-(1.015) B$.

Proof. Let $j \in\{0,1, \ldots, Y\}$ satisfy (4.46). Lemma 4.7, (4.45) and (4.15) give us the conclusion.

Lemma 4.9. If $\left(x_{1}, x_{2}\right) \in R^{2}, j \in\{0,1, \ldots, Y\},\left|x_{1}-j X-A\right| \leqq\left(10^{4} C / D\right) E$ and $\left|x_{2}\right| \leqq$ $E$, then $\sum_{n=0}^{Y} F_{1}^{*}\left(x_{1}-n X, x_{2}\right) \geqq(6.985) B$.

Proof. From (4.18) we obtain $\left|x_{1}-j X\right| \leqq\left|x_{1}-j X-A\right|+|A| \leqq\left(10^{4} C / D\right) E+$ $X / 4<X / 4+X / 4=X / 2$, which implies (4.46). Now Lemma 4.7, (4.45) and (4.16) yield the desired conclusion.

Lemma 4.10. If $\left(x_{1}, x_{2}\right) \in R^{2}$ and $\left|\left(x_{1}-n X, x_{2}\right)\right|>r / 10$ holds for all $n \in\{0,1, \ldots, Y\}$, then $\sum_{n=0}^{Y}\left|F^{*}\left(x_{1}-n X, x_{2}\right)\right| \leqq 10^{-3} \varepsilon^{2} B$.

Proof. Since (4.33) implies $\left|\left(x_{1}-n X, x_{2}\right)\right|>r / 10>2|A|$, we can use (4.17), (4.45), and the second part of (4.33) to conclude

$$
\sum_{n=0}^{Y}\left|F^{*}\left(x_{1}-n X, x_{2}\right)\right| \leqq 2 C \sum_{n=0}^{Y}\left|\left(x_{1}-n X, x_{2}\right)\right|^{-4} \leqq 2 C \sum_{n=0}^{Y}(r / 10)^{-4} \leqq 10^{-3} \varepsilon^{2} B .
$$

Lemma 4.11. If $h: P \rightarrow R$ is defined by

$$
h\left(x_{1}, x_{2}\right)=v_{2}\left(x_{1}, x_{2}\right) \cdot\left(F^{a, r, s}\left(x_{1}, x_{2}\right)+\sum_{n=0}^{Y} F^{*}\left(x_{1}-n X, x_{2}\right)\right),
$$

where $v_{2}$ is the function in Lemma 4.4 , then

(a) if $j \in\{0,1, \ldots, Y\},\left|x_{1}-j X-A\right| \leqq \tau d$ and (.02) $r r \leqq x_{2} \leqq(.98) \varepsilon r$, then $h\left(x_{1}, x_{2}\right) \geqq$ (8.005)B,

(b) if $\left|x_{1}\right| \leqq d-r$ and $(.02) \varepsilon r \leqq x_{2} \leqq(.98) \varepsilon r$, then $h\left(x_{1}, x_{2}\right) \geqq(.005) B$,

(c) if $x \in P$ then $h(x) \geqq-\varepsilon^{2}(1.032) B$.

Proof. Using (4.34) we find that the hypotheses of (a) imply

$$
\left|x_{1}-j X-A\right| \leqq \tau d \leqq\left(10^{4} C / D\right) E, \quad 0<x_{2}<E<r .
$$


Also, the last part of Lemma 4.5 gives us $x_{1} \in(r-d, d-r)$. All this, Lemma 4.3 and Lemma 4.9 give us

$$
F_{1}^{a, r, s}\left(x_{1}, x_{2}\right)+\sum_{n=0}^{Y} F_{1}^{*}\left(x_{1}-n X, x_{2}\right) \geqq(1.02) B+(6.985) B=(8.005) B .
$$

The conclusion of (a) follows from the above and (4.29).

Suppose that the hypotheses of (b) hold. As in (a), we get $0<x_{2}<E<r$. Now Lemma 4.3 and Lemma 4.8 yield

$$
F_{1}^{a, r, s}\left(x_{1}, x_{2}\right)+\sum_{n=0}^{Y} F_{1}^{*}\left(x_{1}-n X, x_{2}\right) \geqq(1.02) B-(1.015) B=(.005) B .
$$

As before, the conclusion of (b) follows from (4.29).

Now we prove (c). Since $B, \varepsilon$ are positive (see (4.8), (4.20)), we may assume $\left(x_{1}, x_{2}\right) \in \operatorname{spt}\left(v_{2}\right)$. We will distinguish two cases:

Case I. $\left|\left(x_{1}-j X, x_{2}\right)\right|>r / 10$ for all $j \in\{0,1, \ldots, Y\}$.

In this case, we use (4.25), (4.28), Lemma 4.3, Lemma 4.10 and the positivity of $B, \varepsilon$ to conclude

$$
\begin{aligned}
h\left(x_{1}, x_{2}\right)= & v_{21}\left(x_{1}, x_{2}\right) F_{1}^{a, r, s}\left(x_{1}, x_{2}\right)+v_{22}\left(x_{1}, x_{2}\right) F_{2}^{a, r, s}\left(x_{1}, x_{2}\right) \\
& +v_{2}\left(x_{1}, x_{2}\right) \cdot\left(\sum_{n=0}^{Y} F^{*}\left(x_{1}-n X, x_{2}\right)\right) \\
\geqq & -\varepsilon^{2}(1.03) B-(\varepsilon / 2)(.002) B \varepsilon-10^{-3} \varepsilon^{2} B=-\varepsilon^{2}(1.032) B .
\end{aligned}
$$

Case II. $\left|\left(x_{1}-j X, x_{2}\right)\right| \leqq r / 10$ for some $j \in\{0,1, \ldots, Y\}$.

From (4.32), (4.35) we get

$$
\left|x_{1}\right| \leqq\left|\left(x_{1}, x_{2}\right)\right| \leqq|j X|+r / 10 \leqq Y X+r / 10=d / 40+r / 10<d-r .
$$

Now, the assumption $\left(x_{1}, x_{2}\right) \in \operatorname{spt}\left(v_{2}\right)$ and (4.26) imply $x_{2} \notin[E, r / 10]$. From this fact and $\left|x_{2}\right| \leqq\left|\left(x_{1}-j X, x_{2}\right)\right| \leqq r / 10$ we get $x_{2}<E$. The assumption $\left(x_{1}, x_{2}\right) \in P$ gives $x_{2}>0$. All this and (4.30) imply $v_{21}\left(x_{1}, x_{2}\right) \geqq 0, v_{22}\left(x_{1}, x_{2}\right)=0$. The above, (4.8), (4.25), Lemma 4.3 and Lemma 4.8 give us

$$
\begin{aligned}
h\left(x_{1}, x_{2}\right) & =v_{21}\left(x_{1}, x_{2}\right)\left(F_{1}^{a, r, s}\left(x_{1}, x_{2}\right)+\sum_{n=0}^{Y} F_{1}^{*}\left(x_{1}-n X, x_{2}\right)\right) \\
& \geqq v_{21}\left(x_{1}, x_{2}\right)((1.02) B-(1.015) B) \geqq 0>-\varepsilon^{2}(1.032) B .
\end{aligned}
$$

This concludes the proof of Lemma 4.11.

We recall (4.11) and set

$$
\begin{aligned}
& f_{1}=f^{a, r, s}+\sum_{n=0}^{Y}\left(f^{a^{\prime}+n X, r^{\prime}, s^{\prime}}+f^{a^{\prime \prime}+n X, r^{\prime \prime}, s^{\prime \prime}}+f^{n X, 1,1}\right), \\
& v_{1}=z^{a, r, s}+\sum_{n=0}^{Y}\left(z^{a^{\prime}+n X, r^{\prime}, s^{\prime}}+z^{a^{\prime \prime}+n X, r^{\prime \prime}, s^{\prime \prime}}+z^{n X, 1,1}\right), \\
& U_{1}=U^{a, r} \cup \bigcup_{n=0}^{Y}\left(U^{a^{\prime}+n X, r^{\prime}} \cup U^{a^{\prime \prime}+n X, r^{\prime \prime}} \cup U^{n X, 1}\right),
\end{aligned}
$$




$$
K_{1}=K^{a, r} \cup \bigcup_{n=0}^{Y}\left(K^{a^{\prime}+n X, r^{\prime}} \cup K^{a^{\prime \prime}+n X, r^{\prime \prime}} \cup K^{n X, 1}\right) .
$$

Lemma 4.12. The sets $U^{a, r}, U^{a^{\prime}+n^{\prime} X, r^{\prime}}, U^{a^{\prime \prime}+n^{\prime \prime} X, r^{\prime \prime}}, U^{n X, 1}$ (where $n, n^{\prime}, n^{\prime \prime}$ range over $\{0,1, \ldots, Y\}$ ) have disjoint closures.

Proof. This follows from (4.1), (4.11) and all three assertions of Lemma 4.6.

With the aid of Lemma 4.12, (4.12) and (4.1)-(4.6) we conclude:

$$
\begin{aligned}
& K_{1} \subset U_{1} \subset P, K_{1} \text { is compact, } U_{1} \text { is open, closure }\left(U_{1}\right) \subset P, \\
& f_{1} \in C_{c}^{\infty}(P, R), \quad v_{1} \in C_{c}^{\infty}\left(P, R^{2}\right), \quad \operatorname{spt}\left(v_{1}\right) \subset K_{1}, \\
& f_{1} \geqq 0, \quad f_{1}(x)=0 \quad \text { if } \quad x \notin U_{1}, \quad f_{1}(x)>\left|v_{1}(x)\right| \text { if } \quad x \in U_{1}, \\
& x_{2} \frac{\partial}{\partial x_{1}} v_{11}\left(x_{1}, x_{2}\right)+x_{2} \frac{\partial}{\partial x_{2}} v_{12}\left(x_{1}, x_{2}\right)+v_{12}\left(x_{1}, x_{2}\right)=0, \\
& L\left(f_{1}\right)(x) \geqq 0 \quad \text { if } \quad x \notin K_{1}, \quad L\left(f_{1}\right)(x)>0 \quad \text { if } \quad x \in U_{1} \sim K_{1} .
\end{aligned}
$$

Lemma 4.13. If $\left(x_{1}, x_{2}\right) \in P$, then

$$
\nabla\left(p\left[0, f_{1}\right]-p\left[v_{1}, f_{1}\right]\right)\left(x_{1}, x_{2}\right)=F^{a, r, s}\left(x_{1}, x_{2}\right)+\sum_{n=0}^{Y} F^{*}\left(x_{1}-n X, x_{2}\right) .
$$

Proof. This follows from (4.11)-(4.13), (4.45), (4.47), Lemma 2.2 and Lemma 4.12.

Now we adopt the construction in (6.42)-(6.45) of [4]. Recall that the function $w$ of [4] is called $v_{2}$ here. This gives us $U_{2}, K_{2}, k$ satisfying (4.53)-(4.56):

$$
\begin{aligned}
& U_{2}=\left((-d, d) \times\left(10^{-3} \varepsilon r, r\right)\right) \sim([r-d, d-r] \times[E, r / 10]), \\
& \operatorname{spt}\left(v_{2}\right) \subset K_{2} \subset U_{2}, K_{2} \text { is compact, } k \in C_{c}^{\infty}(P, R), \quad 0 \leqq k \leqq 1, \\
& k(x)=0 \quad \text { if } \quad x \notin U_{2}, k(x)>0 \quad \text { if } \quad x \in U_{2}, k(x)=1 \quad \text { if } \quad x \in \operatorname{spt}\left(v_{2}\right), \\
& L(k)(x) \geqq 0 \quad \text { if } \quad x \notin K_{2}, L(k)(x)>0 \quad \text { if } \quad x \in U_{2} \sim K_{2} .
\end{aligned}
$$

We choose a constant $\mu$ satisfying

$$
\mu^{2}>10\left(\left\|v_{2}\right\|_{\infty}^{2}+1\right), \quad \mu>100\left\|f_{1}\right\|_{\infty},
$$

and we set

$$
f_{2}=\mu k, \quad T=\left(\mu^{2}-\left\|v_{2}\right\|_{\infty}^{2}-1\right) /\left(\varepsilon^{2}(1.032) B\right) .
$$

Lemma 4.14. We have the following four properties:

$$
\begin{aligned}
& \operatorname{spt}\left(f_{1}\right) \subset([a-r, a+r] \times[r / 8,7 r / 8]) \cup((r-d, d-r) \times(E, r / 10)), \\
& \operatorname{spt}\left(f_{2}\right)=\left([-d, d] \times\left[10^{-3} \varepsilon r, r\right]\right) \sim((r-d, d-r) \times(E, r / 10)), \\
& \operatorname{spt}\left(f_{1}\right) \text { and } \operatorname{spt}\left(f_{2}\right) \text { are disjoint, } \\
& \left\|f_{2}\right\|_{\infty}=\mu, \quad f_{2}(x)=\mu \quad \text { if } \quad x \in \operatorname{spt}\left(v_{2}\right) .
\end{aligned}
$$

Proof. Inclusion (4.59) follows from the second part of Lemma 4.6, (4.1), (4.12) and (4.47). Identity (4.60) is a consequence of (4.53), (4.55), (4.58). The last part of 
Lemma 4.6 and (4.59), (4.60) give us (4.61). Finally, (4.54), (4.55), (4.58) yield (4.62).

Lemma 4.15. There exists $\theta>0$ such that (4.63), (4.64) hold:

$$
\begin{aligned}
& \left(\mu^{2}+T(.005) B\right)^{1 / 2}-\theta>\tau^{-1} \cdot\left\|f_{1}\right\|_{\infty}, \\
& \left(\mu^{2}+T(8.005) B\right)^{1 / 2}-\theta>\tau^{-1}\left(\left\|f_{1}\right\|_{\infty}+\left\|f_{2}\right\|_{\infty}\right) .
\end{aligned}
$$

Proof. Using (4.58), (4.57) we find

$$
T B=\left(\mu^{2}-\left\|v_{2}\right\|_{\infty}^{2}-1\right) /\left(\varepsilon^{2}(1.032)\right)>(.9) \mu^{2} /\left(\varepsilon^{2}(1.032)\right) .
$$

This inequality and (4.31), (4.57), (4.62) yield

$$
\begin{aligned}
& T(.005) B>10^{-4} \mu^{2} /\left((.48)^{2} \varepsilon^{2}\right)>\tau^{-2}\left\|f_{1}\right\|_{\infty}^{2}, \\
& T(8.005) B>(1.01)^{2} \mu^{2} /\left((.48)^{2} \varepsilon^{2}\right)=\tau^{-2}(\mu / 100+\mu)^{2}>\tau^{-2}\left(\left\|f_{1}\right\|_{\infty}+\left\|f_{2}\right\|_{\infty}\right)^{2} .
\end{aligned}
$$

Lemma 4.16. If $x \in U_{2}$, then

$$
\left(f_{2}(x)\right)^{2}-T v_{2}(x) \cdot \nabla\left(p\left[v_{1}, f_{1}\right]-p\left[0, f_{1}\right]\right)(x)>\left|v_{2}(x)\right|^{2} .
$$

Proof. If $x \notin \operatorname{spt}\left(v_{2}\right)$, then the inequality reduces to $\left(f_{2}(x)\right)^{2}>0$, which is a consequence of $x \in U_{2}$ and (4.55), (4.57), (4.58). If $x \in \operatorname{spt}\left(v_{2}\right)$, then Lemma 4.13, (4.62), part $(c)$ of Lemma 4.11 and (4.58) give us

$$
\begin{aligned}
& \left(f_{2}(x)\right)^{2}-T v_{2}(x) \cdot \nabla\left(p\left[v_{1}, f_{1}\right]-p\left[0, f_{1}\right]\right)(x) \\
& \quad=\mu^{2}+T v_{2}(x) \cdot\left(F^{a, r, s}(x)+\sum_{n=0}^{Y} F^{*}\left(x_{1}-n X, x_{2}\right)\right) \\
& \quad \geqq \mu^{2}-T \varepsilon^{2}(1.032) B=\left\|v_{2}\right\|_{\infty}^{2}+1>\left|v_{2}(x)\right|^{2} .
\end{aligned}
$$

Lemma 4.17. If $\left(y_{1}, y_{2}\right) \in \operatorname{spt}\left(f_{1}\right) \cup \operatorname{spt}\left(f_{2}\right), z=\left(z_{1}, z_{2}\right) \in P, z_{1}=\tau y_{1}+A+j X$ for some $j \in\{0,1, \ldots, Y\},(.02) \varepsilon r \leqq z_{2} \leqq(.98) \varepsilon r$ and

$$
Q=\left(f_{2}(z)\right)^{2}-T v_{2}(z) \cdot \nabla\left(p\left[v_{1}, f_{1}\right]-p\left[0, f_{1}\right]\right)(z),
$$

then $Q>\left(\tau^{-1}\left(f_{1}+f_{2}\right)\left(y_{1}, y_{2}\right)+\theta\right)^{2}$.

Proof. Parts (4.59), (4.60) of Lemma 4.14 and the last part of Lemma 4.5 give us

$$
y_{1} \in[a-r, a+r] \cup[-d, d] \text {, hence } z_{1} \in(r-d, d-r) .
$$

Hence (4.29), (4.62) yield

$$
z \in(r-d, d-r) \times[(.02) \varepsilon r, \quad(.98) \varepsilon r] \subset \operatorname{spt}\left(v_{2}\right), \text { hence } f_{2}(z)=\mu .
$$

Now (4.66) and Lemma 4.13 imply

$$
Q=\mu^{2}+T v_{2}\left(z_{1}, z_{2}\right) \cdot\left(F^{a, r, s}\left(z_{1}, z_{2}\right)+\sum_{n=0}^{Y} F^{*}\left(z_{1}-n X, z_{2}\right)\right) .
$$

From (4.65) we get two cases: $y_{1} \in[a-r, a+r]$ and $y_{1} \in[-d, d]$. Using (4.67), (4.66), part (b) of Lemma 4.11 and (4.63), we get

$$
Q \geqq \mu^{2}+T(.005) B>\left(\tau^{-1}\left\|f_{1}\right\|_{\infty}+\theta\right)^{2} \geqq\left(\tau^{-1} f_{1}\left(y_{1}, y_{2}\right)+\theta\right)^{2} .
$$

The conclusion follows in the case $y_{1} \in[a-r, a+r]$ because (4.60) and the third 
part of Lemma 4.6 imply $\left(y_{1}, y_{2}\right) \notin \operatorname{spt}\left(f_{2}\right)$. If $y_{1} \in[-d, d]$ then (4.67), the hypothesis $z_{1}=\tau y_{1}+A+j X$, part (a) of Lemma 4.11 and (4.64) yield

$$
Q \geqq \mu^{2}+T(8.005) B>\left(\tau^{-1}\left(\left\|f_{1}\right\|_{\infty}+\left\|f_{2}\right\|_{\infty}\right)+\theta\right)^{2} \geqq\left(\tau^{-1}\left(f_{1}+f_{2}\right)\left(y_{1}, y_{2}\right)+\theta\right)^{2} .
$$

The conclusion also follows in this case.

Lemma 4.18. If $\left(x_{1}, x_{2}, x_{3}\right) \in R^{3},\left(x_{1},\left(x_{2}^{2}+x_{3}^{2}\right)^{1 / 2}\right) \in \operatorname{spt}\left(f_{1}\right) \cup \operatorname{spt}\left(f_{2}\right), j \in\{0,1, \ldots, Y\}$ and

$$
z=\left(z_{1}, z_{2}\right)=\left(\tau x_{1}+A+j X,\left(\left(\tau x_{2}-\varepsilon r / 2\right)^{2}+\left(\tau x_{3}\right)^{2}\right)^{1 / 2}\right),
$$

then $\left(z_{1}, z_{2}\right) \in P$ (i.e. $\left.z_{2}>0\right)$ and

$$
\begin{aligned}
& \left(\left(f_{2}(z)\right)^{2}-T v_{2}(z) \cdot \nabla\left(p\left[v_{1}, f_{1}\right]-p\left[0, f_{1}\right]\right)(z)\right)^{1 / 2} \\
& \quad>\tau^{-1}\left(f_{1}+f_{2}\right)\left(x_{1},\left(x_{2}^{2}+x_{3}^{2}\right)^{1 / 2}\right)+\theta .
\end{aligned}
$$

Proof. In view of Lemma 4.17, all we have to show is (.02) $\varepsilon r \leqq z_{2} \leqq(.98) \varepsilon r$. Since Lemma 4.14 implies $\left(x_{2}^{2}+x_{3}^{2}\right)^{1 / 2} \leqq r$, we can use (4.31) to obtain that $\left(\tau x_{2}+\right.$ $\left.\varepsilon r / 2, \tau x_{3}\right)=\left((.48) \varepsilon x_{2}+\varepsilon r / 2,(.48) \varepsilon x_{3}\right)$ is contained in the circular disc with center $(\varepsilon r / 2,0)$ and radius $(.48) \varepsilon r$. This disc is contained in the annulus with center $(0,0)$ and radii $\varepsilon r / 2-(.48) \varepsilon r=(.02) \varepsilon r$ and $\varepsilon r / 2+(.48) \varepsilon r=(.98) \varepsilon r$.

\section{Section 5. The Cantor Set}

We will use the construction in Sect. 4. In order to apply a result from ref. [4], we will first establish (5.1)-(5.7) for $i=1,2$. Using (4.48), (4.53), (4.54), $\varepsilon>0$ and $r>0$ (see (4.20), (4.33)), we get

$$
K_{i} \subset U_{i} \subset P, K_{i} \text { is compact, } U_{i} \text { is open, closure }\left(U_{i}\right) \subset P \text {. }
$$

From (4.49), (4.54), (4.57), (4.58) and Lemma 4.4 we obtain

$$
f_{i} \in C_{c}^{\infty}(P, R), \quad v_{i}=\left(v_{i 1}, v_{i 2}\right) \in C_{c}^{\infty}\left(P, R^{2}\right) .
$$

The identity $\operatorname{spt}\left(f_{i}\right)=\operatorname{closure}\left(U_{i}\right)$ follows from (4.50), (4.55), (4.57) and (4.58). Therefore, we can use (4.61), (5.2), (4.49), (4.54) to write

$$
\text { closure }\left(U_{1}\right) \text { and closure }\left(U_{2}\right) \text { are disjoint compact sets, spt }\left(v_{i}\right) \subset K_{i} \text {. }
$$

If $x \in \operatorname{spt}\left(v_{2}\right)$, then (4.58), (4.55), (4.57) imply $f_{2}(x)=\mu k(x)=\mu>\left|v_{2}(x)\right|$. If $x \in U_{2}$ and $x \notin \operatorname{spt}\left(v_{2}\right)$, then (4.58), (4.57), (4.55) give us $f_{2}(x)>0=\left|v_{2}(x)\right|$. These computations and (4.50), (4.54), (4.55), (4.58) yield

$$
f_{i} \geqq 0, \quad f_{i}(x)=0 \quad \text { if } \quad x \notin U_{i}, \quad f_{i}(x)>\left|v_{i}(x)\right| \quad \text { if } \quad x \in U_{i} .
$$

Identities (4.27) and (4.51) imply

$$
x_{2} \frac{\partial}{\partial x_{1}} v_{i 1}\left(x_{1}, x_{2}\right)+x_{2} \frac{\partial}{\partial x_{2}} v_{i 2}\left(x_{1}, x_{2}\right)+v_{i 2}\left(x_{1}, x_{2}\right)=0 \text {. }
$$

Finally, Lemma 4.16, (4.52) and (4.56)-(4.58) give

$$
\left(f_{2}(x)\right)^{2}-T v_{2}(x) \cdot \nabla\left(p\left[v_{1}, f_{1}\right]-p\left[0, f_{1}\right]\right)(x)>\left|v_{2}(x)\right|^{2} \quad \text { if } \quad x \in U_{2},
$$




$$
L\left(f_{i}\right)(x) \geqq 0 \quad \text { if } \quad x \notin K_{i}, \quad L\left(f_{i}\right)(x)>0 \quad \text { if } \quad x \in U_{i} \sim K_{i} .
$$

Lemma (4.15), (4.57), (4.58) and (4.8) give us $T>0$ and $\theta>0$. These facts and (5.1)-(5.7) are the hypotheses of Sect. 3 of [4]. Therefore, we may use Lemma 3.1 of [4] to obtain $\delta, g_{1}, g_{2}, h_{1}, h_{2}$ satisfying (5.8)-(5.15):

$\delta>0, \quad g_{i} \in C_{c}^{\infty}(P, R), \quad h_{i}: P \times(-\delta, T+\delta) \rightarrow R$ is a $C^{\infty}$ function,

$\operatorname{spt}\left(g_{i}\right) \subset U_{i}, \quad \operatorname{spt}\left(v_{i}\right) \subset\left\{x: g_{i}(x)=1\right\}, \quad 0 \leqq g_{i}(x) \leqq 1$ if $x \in P$,

$h_{i} \geqq 0, \quad$ if $\quad x \in \operatorname{spt}\left(g_{i}\right)$ then $h_{i}(x, t)>\left|v_{i}(x)\right|$,

$h_{i}(x, t)=f_{i}(x)$ if $\quad x \notin \operatorname{spt}\left(g_{i}\right)$,

$\left(h_{1}(x, s)\right)^{2}=\left(f_{1}(x)\right)^{2}-2 s \delta g_{1}(x)$,

$\left(h_{2}(x, s)\right)^{2}=\left(f_{2}(x)\right)^{2}-2 s \delta g_{2}(x)-\int_{0}^{s} v_{2}(x) \cdot \nabla\left(p\left[v_{1}, h_{1, t}\right]-p\left[0, h_{1, t}\right]\right)(x) d t$,

where $h_{i, t}(x)=h_{i}(x, t)$,

$h_{2}(x, T)+\theta>\left(\left(f_{2}(x)\right)^{2}-T v_{2}(x) \cdot \nabla\left(p\left[v_{1}, f_{1}\right]-p\left[0, f_{1}\right]\right)(x)\right)^{1 / 2} \quad$ if $\quad x \in P$,

$L\left(h_{i, t}\right)(x) \geqq 0 \quad$ if $\quad g_{i}(x)<1 \quad\left(\right.$ where $h_{i, t}(x)=h_{i}(x, t)$ as in $\left.(5.13)\right)$.

Properties (5.4), (5.9), (5.11) imply

$$
h_{i}(x, t)=0 \quad \text { if } \quad x \notin \operatorname{closure}\left(U_{i}\right)=\operatorname{spt}\left(f_{i}\right) .
$$

Also, (5.9) and (5.10) yield

$$
h_{i}(x, t)>\left|v_{i}(x)\right| \quad \text { if } \quad x \in \operatorname{spt}\left(v_{i}\right)
$$

In view of (5.2), (5.3), (5.8), (5.10), (5.16), (5.17), we may fix $v>0$ such that the following inequality holds:

$$
\begin{aligned}
& v u\left[a v_{i}, h_{i, t}\right](x) \cdot \Delta\left(u\left[a v_{i}, h_{i, t}\right]\right)(x) \geqq-\delta / 4 \\
& \text { if }(x, t) \in P \times[0, T], \quad a \in[-1,1] \text { and } i \in\{1,2\} .
\end{aligned}
$$

We recall (4.8), (4.18), (4.21), (4.31) and make the following definitions:

$$
\begin{aligned}
\beta_{n}: R & \rightarrow R \text { is given by } \beta_{n}(x)=\tau x+A+n X \text { for } n \in\{0,1, \ldots, Y\}, \\
M(Z) & =\left\{m=\left(m_{1}, m_{2}, \ldots, m_{Z}\right): m_{i} \in\{0,1, \ldots, Y\}\right\} \text { for } Z=1,2,3, \ldots, \\
\pi_{m} & =\beta_{m_{1}} \circ \beta_{m_{2}} \circ \cdots \circ \beta_{m_{Z}} \text { if } m=\left(m_{1}, m_{2}, \ldots, m_{Z}\right) \in M(Z), \\
Q & =[a-r, a+r] \cup[-d, d] .
\end{aligned}
$$

If $\left(x_{1}, x_{2}\right) \in P, \quad t \in(-\delta, T+\delta), \quad i \in\{1,2\}, \quad m=\left(m_{1}, m_{2}, \ldots, m_{Z}\right) \in M(Z)$,

we set

$$
\begin{array}{ll}
f_{i}^{m}\left(x_{1}, x_{2}\right)=f_{i}\left(\pi_{m}^{-1}\left(\tau^{Z} x_{1}\right), x_{2}\right), & v_{i}^{m}\left(x_{1}, x_{2}\right)=v_{i}\left(\pi_{m}^{-1}\left(\tau^{Z} x_{1}\right), x_{2}\right), \\
g_{i}^{m}\left(x_{1}, x_{2}\right)=g_{i}\left(\pi_{m}^{-1}\left(\tau^{Z} x_{1}\right), x_{2}\right), & h_{i}^{m}\left(x_{1}, x_{2}, t\right)=h_{i}\left(\pi_{m}^{-1}\left(\tau^{Z} x_{1}\right), x_{2}, t\right) .
\end{array}
$$

Lemma 5.1. If $Z \in\{1,2,3, \ldots\},\left\{m, m^{\prime}\right\} \subset M(Z)$ and $m \neq m^{\prime}$, then $\pi_{m}(Q)$ and $\pi_{m^{\prime}}(Q)$ are disjoint sets. 
Proof. Since (4.33) implies $d-r<d$, we can use (5.22) and Lemma 4.5 to obtain

$$
\begin{aligned}
& \beta_{j}(Q) \subset Q, \\
& \beta_{j}(Q) \text { and } \beta_{j^{\prime}}(Q) \text { are disjoint if } j \neq j^{\prime} .
\end{aligned}
$$

Let $I$ be the smallest integer $i$ such that $m_{i} \neq m_{i}^{\prime}$. Inclusion (5.24) gives

$$
\left(\beta_{m_{I}} \circ \beta_{m_{I+1}} \circ \cdots \circ \beta_{m_{Z}}\right)(Q) \subset \beta_{m_{I}}(Q),\left(\beta_{m_{I}^{\prime}} \circ \beta_{m_{I+1}^{\prime}} \circ \cdots \circ \beta_{m_{Z}^{\prime}}\right)(Q) \subset \beta_{m_{I}^{\prime}}(Q) .
$$

Therefore, (5.25) implies that the sets

$$
\left(\beta_{m_{I}} \circ \cdots \circ \beta_{m_{Z}}\right)(Q) \text { and }\left(\beta_{m_{I}^{\prime}} \circ \cdots \circ \beta_{m_{Z}^{\prime}}\right)(Q)
$$

are disjoint. We obtain the conclusion by applying the one-to-one function $\beta_{m_{1}} \circ \cdots \circ \beta_{m_{I-1}}=\beta_{m_{1}^{\prime}} \circ \cdots \circ \beta_{m_{I-1}^{\prime}}$ to both sets in (5.26).

Lemma 5.2. If $Z \in\{1,2,3, \ldots\}$, then the sets $\operatorname{spt}\left(f_{i}^{m}\right)$ (where $\left.i \in\{1,2\}, m \in M(Z)\right)$ are disjoint.

Proof. From Lemma 4.14, $d-r<d$ and (5.22) we get

$$
\left\{x_{1}:\left(x_{1}, x_{2}\right) \in \operatorname{spt}\left(f_{i}\right) \text { for some } x_{2} \text { and some } i\right\} \subset Q \text {. }
$$

Now (5.23) yields

$$
\left\{x_{1}:\left(x_{1}, x_{2}\right) \in \operatorname{spt}\left(f_{i}^{m}\right) \text { for some } x_{2} \text { and } i\right\} \subset\left\{x_{1}: \tau^{Z} x_{1} \in \pi_{m}(Q)\right\} .
$$

The above and Lemma 5.1 imply that $\operatorname{spt}\left(f_{i}^{m}\right)$ and $\operatorname{spt}\left(f_{i^{\prime}}^{m^{\prime}}\right)$ are disjoint if $m \neq m^{\prime}$. Finally, (4.61) and (5.23) imply that $\operatorname{spt}\left(f_{1}^{m}\right)$ and $\operatorname{spt}\left(f_{2}^{m}\right)$ are disjoint for every $m \in M(Z)$.

Lemma 5.3. If $Z$ is a positive integer, $m \in M(Z), n \in M(Z+1), m_{i}=n_{i}$ for $i \leqq Z$, $\left(x_{1}, x_{2}, x_{3}\right) \in R^{3}$ and

$$
\left(x_{1},\left(x_{2}^{2}+x_{3}^{2}\right)^{1 / 2}\right) \in \operatorname{spt}\left(f_{1}^{n}\right) \cup \operatorname{spt}\left(f_{2}^{n}\right),
$$

then $\left(\left(\tau x_{2}+\varepsilon r / 2\right)^{2}+\left(\tau x_{3}\right)^{2}\right)^{1 / 2}>0$ and

$$
h_{2}^{m}\left(\tau x_{1},\left(\left(\tau x_{2}+\varepsilon r / 2\right)^{2}+\left(\tau x_{3}\right)^{2}\right)^{1 / 2}, T\right)>\tau^{-1}\left(f_{1}^{n}+f_{2}^{n}\right)\left(x_{1},\left(x_{2}^{2}+x_{3}^{2}\right)^{1 / 2}\right) .
$$

Proof. We set $j=n_{Z+1}$ and

$$
z=\left(z_{1}, z_{2}\right)=\left(\beta_{j}\left(\pi_{n}^{-1}\left(\tau^{Z+1} x_{1}\right)\right),\left(\left(\tau x_{2}+\varepsilon r / 2\right)^{2}+\left(\tau x_{3}\right)^{2}\right)^{1 / 2}\right) .
$$

Since (5.27) and (5.23) imply

$$
\left(\pi_{n}^{-1}\left(\tau^{Z+1} x_{1}\right),\left(x_{2}^{2}+x_{3}^{2}\right)^{1 / 2}\right) \in \operatorname{spt}\left(f_{1}\right) \cup \operatorname{spt}\left(f_{2}\right),
$$

we can use Lemma 4.18 and (5.19), (5.14), (5.23) to conclude $\left(z_{1}, z_{2}\right) \in P$ (which means $\left.\left(\left(\tau x_{2}+\varepsilon r / 2\right)^{2}+\left(\tau x_{3}\right)^{2}\right)^{1 / 2}=z_{2}>0\right)$ and

$$
\begin{aligned}
h_{2}(z, T) & >\left(\left(f_{2}(z)\right)^{2}-T v_{2}(z) \cdot \nabla\left(p\left[v_{1}, f_{1}\right]-p\left[0, f_{1}\right]\right)(z)\right)^{1 / 2}-\theta \\
& >\tau^{-1}\left(f_{1}+f_{2}\right)\left(\pi_{n}^{-1}\left(\tau^{Z+1} x_{1}\right),\left(x_{2}^{2}+x_{3}^{2}\right)^{1 / 2}\right) \\
& =\tau^{-1}\left(f_{1}^{n}+f_{2}^{n}\right)\left(x_{1},\left(x_{2}^{2}+x_{3}^{2}\right)^{1 / 2}\right) .
\end{aligned}
$$

We also have $\pi_{n}=\beta_{n_{1}} \circ \cdots \circ \beta_{n_{Z}} \circ \beta_{j}=\beta_{m_{1}} \circ \cdots \circ \beta_{m_{Z}} \circ \beta_{j}=\pi_{m} \circ \beta_{j}$, which implies $\pi_{n}^{-1}=$ 
$\beta_{j}^{-1} \circ \pi_{m}^{-1}$ and $\beta_{j} \circ \pi_{n}^{-1}=\pi_{m}^{-1}$. Hence we can use (5.23) and say

$$
h_{2}^{m}\left(\tau x_{1}, z_{2}, T\right)=h_{2}\left(\pi_{m}^{-1}\left(\tau^{Z} \tau x_{1}\right), z_{2}, T\right)=h_{2}\left(\beta_{j}\left(\pi_{n}^{-1}\left(\tau^{Z+1} x_{1}\right)\right), z_{2}, T\right)=h_{2}(z, T) .
$$

The conclusion follows from this identity and the previous inequality.

Lemma 5.4. There exists $\xi_{Z}>0$ such that

$$
\begin{aligned}
& \sum_{m \in M(Z)}\left(h_{1}^{m}+h_{2}^{m}\right)\left(\tau x_{1},\left(\left(\tau x_{2}+\varepsilon r / 2\right)^{2}+\left(\tau x_{3}\right)^{2}\right)^{1 / 2}, T\right) \\
& \geqq \xi_{Z}+\sum_{n \in M(Z+1)} \tau^{-1}\left(f_{1}^{n}+f_{2}^{n}\right)\left(x_{1},\left(x_{2}^{2}+x_{3}^{2}\right)^{1 / 2}\right)
\end{aligned}
$$

holds if $\left(x_{1},\left(x_{2}^{2}+x_{3}^{2}\right)^{1 / 2}\right) \in \bigcup_{n \in M(Z+1)}\left(\operatorname{spt}\left(f_{1}^{n}\right) \cup \operatorname{spt}\left(f_{2}^{n}\right)\right)$.

Proof. This follows from Lemma 5.2 (applied to $M(Z+1)$ ), Lemma 5.3, the compactness of $\operatorname{spt}\left(f_{i}^{n}\right)$ and $h_{i}^{m} \geqq 0$ (see (5.2), (5.10), (5.23)).

Lemma 5.5. For every positive integer $Z$, there exist $\eta_{Z}>0$ and $C^{\infty}$ functions $u^{Z}: R^{3} \times\left(-\eta_{Z}, T+\eta_{Z}\right) \rightarrow R^{3}$ and $p^{Z}: R \times\left(-\eta_{Z}, T+\eta_{Z}\right) \rightarrow R$ satisfying the following:

$$
\begin{aligned}
& u^{Z}\left(x_{1}, x_{2}, x_{3}, t\right)=0 \quad \text { if } \quad\left(x_{1},\left(x_{2}^{2}+x_{3}^{2}\right)^{1 / 2}\right) \notin \bigcup_{m \in M(Z)}\left(\operatorname{spt}\left(f_{1}^{m}\right) \cup \operatorname{spt}\left(f_{2}^{m}\right)\right) \text {, } \\
& \sum_{i=1}^{3} \frac{\partial u_{i}^{Z}}{\partial x_{i}}=0 \\
& p^{Z}(x, t)=\int_{R^{3}} \sum_{i=1}^{3} \sum_{j=1}^{3} \frac{\partial u_{j}^{Z}}{\partial x_{i}}(y, t) \frac{\partial u_{i}^{Z}}{\partial x_{j}}(y, t)(4 \pi|x-y|)^{-1} d y, \\
& \frac{\partial}{\partial t} 2^{-1}\left|u^{Z}(x, t)\right|^{2} \leqq-u^{Z}(x, t) \cdot \nabla\left(2^{-1}\left|u^{Z}\right|^{2}+p^{Z}\right)(x, t)+v u^{Z}(x, t) \cdot \Delta u^{Z}(x, t) \\
& \text { if } t \in[0, T] \text {, } \\
& \left|u^{Z}\left(x_{1}, x_{2}, x_{3}, 0\right)\right|=\sum_{m \in M(Z)}\left(h_{1}^{m}+h_{2}^{m}\right)\left(x_{1},\left(x_{2}^{2}+x_{3}^{2}\right)^{1 / 2}, 0\right) \\
& =\sum_{m \in M(Z)}\left(f_{1}^{m}+f_{2}^{m}\right)\left(x_{1},\left(x_{2}^{2}+x_{3}^{2}\right)^{1 / 2}\right) \\
& \text { if }\left(x_{2}, x_{3}\right) \neq(0,0) \text {, } \\
& || u^{Z}\left(x_{1}, x_{2}, x_{3}, t\right)\left|-\sum_{m \in M(Z)}\left(h_{1}^{m}+h_{2}^{m}\right)\left(x_{1},\left(x_{2}^{2}+x_{3}^{2}\right)^{1 / 2}, t\right)\right| \leqq \xi_{Z} \\
& \text { if } t \in[0, T] \text { and }\left(x_{2}, x_{3}\right) \neq(0,0) \text {. }
\end{aligned}
$$

Proof. We set $C_{i}^{m}=\operatorname{spt}\left(f_{i}^{m}\right)$. If $x \notin C_{i}^{m}$, then the identity $h_{i}^{m}(x, t)=0$ follows from (5.16) and (5.23). In addition, (5.19), (5.21), (5.23) imply that $f_{i}^{m}, v_{i}^{m}, g_{i}^{m}, h_{i}^{m}$ are translations of $f_{i}, v_{i}, g_{i}, h_{i}$. The property $h_{i}^{m}(x, 0)=f_{i}^{m}(x)$ is a consequence of (5.12), (5.13), (5.4), (5.10) and (5.23). Using these properties, (5.1)-(5.23) and Lemma 5.2, we find that the hypotheses of Lemma 3.2 are satisfied when the set $M(Z)$ is placed in one-to-one correspondence with the set $\{1,2, \ldots, M\}$ for some $M$, and the obvious identification is made. The conclusions follow from Lemma 3.2. 
Lemma 5.6. If $Z$ is a positive integer then every $\left(x_{1}, x_{2}, x_{3}\right) \in R^{3}$ satisfies

$$
\left|u^{Z}\left(\tau x_{1}, \tau x_{2}+\varepsilon r / 2, \tau x_{3}, T\right)\right| \geqq \tau^{-1}\left|u^{Z+1}\left(x_{1}, x_{2}, x_{3}, 0\right)\right| .
$$

Proof. If $\left(x_{1},\left(x_{2}^{2}+x_{3}^{2}\right)^{1 / 2}\right) \in \bigcup_{n \in M(Z+1)}\left(\operatorname{spt}\left(f_{1}^{n}\right) \cup \operatorname{spt}\left(f_{2}^{n}\right)\right)$, then the inequality follows from Lemma 5.4 and (5.32), (5.33). Otherwise, we can use (5.28) to conclude $u^{Z+1}\left(x_{1}, x_{2}, x_{3}, 0\right)=0$.

Using the notation

$$
\begin{aligned}
& a_{Z}=\tau^{-Z}\left(\tau^{0}+\tau^{1}+\tau^{2}+\cdots+\tau^{Z-1}\right) \varepsilon r / 2, \\
& b_{Z}=\left(\tau^{0}+\tau^{2}+\tau^{4}+\cdots+\tau^{2 Z-2}\right) T,
\end{aligned}
$$

we recall Lemma 5.5 and set

$$
\begin{gathered}
v^{Z}\left(x_{1}, x_{2}, x_{3}, t\right)=\tau^{-Z} u^{Z}\left(\tau^{-Z} x_{1}, \tau^{-Z} x_{2}-a_{Z}, \tau^{-Z} x_{3},\left(t-b_{Z}\right) \tau^{-2 Z}\right), \\
q^{Z}\left(x_{1}, x_{2}, x_{3}, t\right)=\tau^{-2 Z} p^{Z}\left(\tau^{-Z} x_{1}, \tau^{-Z} x_{2}-a_{Z}, \tau^{-Z} x_{3},\left(t-b_{Z}\right) \tau^{-2 Z}\right) \\
\text { if } Z \in\{1,2,3, \ldots\}, \quad\left(x_{1}, x_{2}, x_{3}\right) \in R^{3} \text { and } b_{Z}-\tau^{2 Z} \eta_{Z}<t<b_{Z+1}+\tau^{2 Z} \eta_{Z} .
\end{gathered}
$$

This definition supersedes the earlier definitions of $v_{i}^{m}$ and $q_{i}^{m}$. From (5.29)-(5.31), (5.35) we obtain

$$
\begin{aligned}
& \sum_{i=1}^{3} \frac{\partial v_{i}^{Z}}{\partial x_{i}}=0 \\
& q^{Z}(x, t)=\int_{R^{3}} \sum_{i=1}^{3} \sum_{j=1}^{3} \frac{\partial v_{j}^{Z}}{\partial x_{i}}(y, t) \frac{\partial v_{i}^{Z}}{\partial x_{j}}(y, t)(4 \pi|x-y|)^{-1} d y \\
& \frac{\partial}{\partial t} 2^{-1}\left|v^{Z}(x, t)\right|^{2} \leqq-v^{Z}(x, t) \cdot \nabla\left(2^{-1}\left|v^{Z}\right|^{2}+q^{Z}\right)(x, t)+v v^{Z}(x, t) \cdot \Delta v^{Z}(x, t) \\
& \quad \text { if } b_{Z} \leqq t \leqq b_{Z+1}
\end{aligned}
$$

Lemma 5.7. If $Z$ is a positive integer, then $\left|v^{Z}\left(x, b_{Z+1}\right)\right| \geqq\left|v^{Z+1}\left(x, b_{Z+1}\right)\right|$.

Proof. We use (5.34), (5.35) and Lemma 5.6 to derive

$$
\begin{aligned}
& \left|v^{Z}\left(x_{1}, x_{2}, x_{3}, b_{Z+1}\right)\right| \\
& \quad=\tau^{-Z}\left|u^{Z}\left(\tau\left(\tau^{-(Z+1)} x_{1}\right), \tau\left(\tau^{-(Z+1)} x_{2}-a_{Z+1}\right)+\varepsilon r / 2, \tau\left(\tau^{-(Z+1)} x_{3}\right), T\right)\right| \\
& \quad \geqq \tau^{-Z} \tau^{-1}\left|u^{Z+1}\left(\tau^{-(Z+1)} x_{1}, \tau^{-(Z+1)} x_{2}-a_{Z+1}, \tau^{-(Z+1)} x_{3}, 0\right)\right| \\
& \quad=\left|v^{Z+1}\left(x_{1}, x_{2}, x_{3}, b_{Z+1}\right)\right| .
\end{aligned}
$$

Lemma 5.8. If $v^{Z}(x, t) \neq 0$ for some $Z, x, t$ then $x_{1} \in(r-d, d-r),\left|x_{2}\right| \leqq \tau r+$ $(1-\tau)^{-1}(\varepsilon r / 2)$ and $\left|x_{3}\right| \leqq \tau r$.

Proof. If $v^{Z}\left(x_{1}, x_{2}, x_{3}, t\right) \neq 0$, then (5.35) and (5.28) imply

$$
\left(\tau^{-Z} x_{1},\left(\left(\tau^{-Z} x_{2}-a_{Z}\right)^{2}+\left(\tau^{-Z} x_{3}\right)^{2}\right)^{1 / 2}\right) \in \operatorname{spt}\left(f_{1}^{m}\right) \cup \operatorname{spt}\left(f_{2}^{m}\right)
$$


for some $m \in M(Z)$. Then (5.23) yields

$$
\left(\pi_{m}^{-1}\left(x_{1}\right),\left(\left(\tau^{-Z} x_{2}-a_{Z}\right)^{2}+\left(\tau^{-Z} x_{3}\right)^{2}\right)^{1 / 2}\right) \in \operatorname{spt}\left(f_{1}\right) \cup \operatorname{spt}\left(f_{2}\right)
$$

Therefore, Lemma 4.14 and $d-r<d$ (see (4.33)) give us

$$
\pi_{m}^{-1}\left(x_{1}\right) \in[a-r, a+r] \cup[-d, d], \quad\left|\tau^{-z} x_{2}-a_{Z}\right| \leqq r, \quad\left|\tau^{-z} x_{3}\right| \leqq r .
$$

The above, (5.21), (5.22), (5.24), the last part of Lemma 4.5, (5.19), $0<\tau<1$ (see (4.32)) and (5.34) yield

$$
\begin{aligned}
& x_{1} \in\left(\beta_{m_{1}} \circ \cdots \circ \beta_{m_{Z}}\right)([a-r, a+r] \cup[-d, d]) \\
& \quad \subset \beta_{m_{1}}([a-r, a+r] \cup[-d, d]) \subset(r-d, d-r), \\
& \left|x_{2}\right| \leqq\left|\tau^{Z} r\right|+\left|\tau^{Z} a_{Z}\right| \leqq \tau r+(1-\tau)^{-1} \varepsilon r / 2,\left|x_{3}\right| \leqq \tau^{Z} r \leqq \tau r .
\end{aligned}
$$

Lemma 5.9. If $Z$ is a positive integer, $\phi: R^{3} \times R \rightarrow R$ is a $C^{\infty}$ function with compact support and $\phi \geqq 0$, then

$$
\begin{aligned}
& \int_{R^{3}} 2^{-1}\left|v^{Z}\left(x, b_{Z+1}\right)\right|^{2} \phi\left(x, b_{Z+1}\right) d x-\int_{R^{3}} 2^{-1}\left|v^{Z}\left(x, b_{Z}\right)\right|^{2} \phi\left(x, b_{Z}\right) d x \\
& \quad+\int_{b_{Z}}^{b_{Z}+1} \int_{R^{3}} v\left|\nabla v^{Z}(x, t)\right|^{2} \phi(x, t) d x d t \\
& \leqq \int_{b_{Z}}^{b_{Z}} \int_{R^{3}}\left(2^{-1}\left|v^{Z}\right|^{2}+q^{Z}\right)(x, t) v^{Z}(x, t) \cdot \nabla \phi(x, t) d x d t \\
& \quad+\int_{b_{Z}}^{b_{Z}+1} \int_{R^{3}} 2^{-1}\left|v^{Z}(x, t)\right|^{2}\left(\frac{\partial \phi}{\partial t}+v \Delta \phi\right)(x, t) d x d t .
\end{aligned}
$$

Proof. The inequality follows when we multiply (5.38) by $\phi(x, t)$, integrate over $R^{3} \times\left[b_{Z}, b_{Z+1}\right]$ and use (5.36).

Recalling $0<\tau<1$ (see (4.32)) and (5.34)-(5.35), we define $u: R^{3} \times[T, \infty) \rightarrow R^{3}$ and $p: R^{3} \times[T, \infty) \rightarrow R$ using the following formulas:

$$
\begin{aligned}
& u(x, t)=v^{Z}(x, t), \quad p(x, t)=q^{Z}(x, t) \quad \text { if } \quad b_{Z} \leqq t<b_{Z+1} \\
& u(x, t)=0, \quad p(x, t)=0 \quad \text { if } \quad t \geqq T\left(1-\tau^{2}\right)^{-1}=\lim _{Z \rightarrow \infty} b_{Z} .
\end{aligned}
$$

From (5.37) we conclude

$$
p(x, t)=\int_{R^{3}} \sum_{i=1}^{3} \sum_{j=1}^{3} \frac{\partial u_{j}}{\partial x_{i}}(y, t) \frac{\partial u_{i}}{\partial x_{j}}(y, t)(4 \pi|x-y|)^{-1} d y .
$$

Lemma 5.10. If $Z$, $\phi$ satisfy the hypotheses of Lemma 5.9 and $\operatorname{spt}(\phi) \subset R^{3} \times(T, \infty)$, then

$$
\begin{gathered}
\int_{R^{3}} 2^{-1}\left|u\left(x, b_{Z+1}\right)\right|^{2} \phi\left(x, b_{Z+1}\right) d x+\int_{T}^{b_{Z+1}} \int_{R^{3}} v|\nabla u(x, t)|^{2} \phi(x, t) d x d t \\
\leqq \\
\int_{T}^{b_{Z+1}} \int_{R^{3}}\left(2^{-1}|u|^{2}+p\right)(x, t) u(x, t) \cdot \nabla \phi(x, t) d x d t \\
\quad+\int_{T}^{b_{Z+1}} \int_{R^{3}} 2^{-1}|u(x, t)|^{2}\left(\frac{\partial \phi}{\partial t}+v \Delta \phi\right)(x, t) d x d t .
\end{gathered}
$$


Proof. We use Lemma 5.9 with $Z$ replaced by $W$, add the resulting inequalities for $W=1,2, \ldots, Z$, and apply $\phi\left(x, b_{1}\right)=\phi(x, T)=0$ and Lemma 5.7, which implies

$$
\begin{aligned}
& \sum_{W=1}^{Z} \int_{R^{3}} 2^{-1}\left|v^{W}\left(x, b_{W+1}\right)\right|^{2} \phi\left(x, b_{W+1}\right) d x \\
& \geqq \sum_{W=1}^{Z} \int_{R^{3}} 2^{-1}\left|v^{W+1}\left(x, b_{W+1}\right)\right|^{2} \phi\left(x, b_{W+1}\right) d x \\
& =\sum_{W=2}^{Z+1} \int_{R^{3}} 2^{-1}\left|v^{W}\left(x, b_{W}\right)\right|^{2} \phi\left(x, b_{W}\right) d x \\
& =\sum_{W=1}^{Z} \int_{R^{3}} 2^{-1}\left|v^{W}\left(x, b_{W}\right)\right|^{2} \phi\left(x, b_{W}\right) d x \\
& \quad+\int_{R^{3}} 2^{-1}\left|u\left(x, b_{Z+1}\right)\right|^{2} \phi\left(x, b_{Z+1}\right) d x .
\end{aligned}
$$

Lemma 5.11. The function $\nabla u$ is square integrable and $\int_{R^{3}}|u(x, t)|^{2} d x$ is a nonincreasing real-valued function of $t$.

Proof. Properties (5.36), (5.38) and Lemma 5.8 imply the usual energy inequality for $v^{Z}$ on the set $R^{3} \times\left[b_{Z}, b_{Z+1}\right]$. The conclusion is pieced together from this fact, (5.39) and Lemma 5.7.

Lemma 5.12. If $T^{\prime}=T\left(1-\tau^{2}\right)^{-1}$, then $\int_{T}^{T_{R^{3}}^{\prime}} \int_{R^{3}}|u(x, t)|^{3} d x d t$ and $\int_{T}^{T^{\prime}} \int_{R^{3}}|u(x, t)||p(x, t)|$ $d x d t$ are finite.

Proof. This follows from Lemma 5.11, Lemma 5.8 and (5.40) in a standard way. See, for example, Lemma 3.2 and Lemma 3.6 of [3].

Lemma 5.13. If $\phi: R^{3} \times R \rightarrow R$ is a $C^{\infty}$ function with compact support, $\phi \geqq 0$ and $\operatorname{spt}(\phi) \subset R^{3} \times(T, \infty)$, then

$$
\begin{aligned}
\int_{T}^{\infty} \int_{R^{3}} v|\nabla u(x, t)|^{2} \phi(x, t) d x d t \leqq & \int_{T}^{\infty} \int_{R^{3}}\left(2^{-1}|u|^{2}+p\right)(x, t) u(x, t) \cdot \nabla \phi(x, t) d x d t \\
& +\int_{T}^{\infty} \int_{R^{3}} 2^{-1}|u(x, t)|^{2}\left(\frac{\partial \phi}{\partial t}+v \Delta \phi\right)(x, t) d x d t .
\end{aligned}
$$

Proof. This is a consequence of the three previous lemmas and the identity $u(x, t)=0$ for $t \geqq T\left(1-\tau^{2}\right)^{-1}=\lim _{Z \rightarrow \infty} b_{Z}$ (see (5.39)).

We set

$$
\begin{aligned}
& S_{Z}=\bigcup_{m \in M(Z)} \pi_{m}[-d, d], \quad S=\bigcap_{Z=1}^{\infty} S_{Z}, \\
& S^{\prime}=\left\{\left(s,(1-\tau)^{-1} \varepsilon r / 2,0,\left(1-\tau^{2}\right)^{-1} T\right): s \in S\right\} .
\end{aligned}
$$


Lemma 5.14. The Hausdorff dimension of $S^{\prime}$ is greater than $\zeta$.

Proof. Lemma 4.5, (5.19) and (4.33) give us $\beta_{k}[-d, d] \subset(r-d, d-r) \subset[-d, d]$, which implies $\left(\pi_{m}^{\circ} \beta_{k}\right)[-d, d] \subset \pi_{m}[-d, d]$. This fact and (5.20), (5.21) yield

$$
S_{Z+1} \subset S_{Z} \subset[-d, d], S_{Z} \text { is compact. }
$$

Using (5.21) we also get

$$
S_{Z+1}=\bigcup_{j=0}^{Y} \beta_{j}\left(S_{Z}\right)
$$

Let $V$ be an open set containing $\bigcup_{j=0}^{Y} \beta_{j}(S)$. There is an open set $W$ containing $S$ such that $\beta_{j}(W) \subset V$ holds for all $j$. From (5.41), (5.43) we obtain the existence of $Z$ satisfying $S_{Z} \subset W$. For this $Z$, we can use (5.41), (5.44) to conclude $S \subset S_{Z+1}=\bigcup_{j=0}^{Y}$ $\beta_{j}\left(S_{Z}\right) \subset \bigcup_{j=0}^{Y} \beta_{j}(W) \subset V$. Since $V$ is an arbitrary open set about $\bigcup_{j=0}^{Y} \beta_{j}(S)$, we conclude $S \subset \bigcup_{j=0}^{Y} \beta_{j}(S)$. The opposite inclusion is immediate from (5.41), (5.43) and (5.44). These properties, (5.41) and (5.43) give us

$$
S=\bigcup_{j=0}^{Y} \beta_{j}(S), S \text { is compact. }
$$

Since (5.22) and (5.25) imply that the sets $\beta_{j}[-d, d]$ are disjoint, we can use (5.41), (5.43) to conclude

$$
\left\{\beta_{j}(S): j=0,1, \ldots, Y\right\} \text { is a family of disjoint sets. }
$$

A theorem of Moran [2, Theorem II] says that (5.45), (5.46) and (5.19) imply $(Y+1) \tau^{\operatorname{dim}(S)}=1$, where $\operatorname{dim}$ is the Hausdorff dimension. This identity, (4.32) and (5.42) yield $\zeta<\operatorname{dim}(S)=\operatorname{dim}\left(S^{\prime}\right)$.

Lemma 5.15. If $s^{\prime} \in S^{\prime}$ and $V$ is an open neighborhood of $s^{\prime}$ in $R^{3} \times(T, \infty)$, then $u$ is not essentially bounded on $V$.

Proof. Definition (5.42) implies $s^{\prime}=\left(s,(1-\tau)^{-1} \varepsilon r / 2,0,\left(1-\tau^{2}\right)^{-1} T\right)$ for some $s \in S$. Let $N$ be a given positive number. Using (4.32), (5.34), (4.57), (4.62), we conclude $0<\tau<1, \lim \tau^{Z} a_{Z}=(1-\tau)^{-1} \varepsilon r / 2, \lim _{Z \rightarrow \infty} b_{Z}=\left(1-\tau^{2}\right)^{-1} T,\left\|f_{2}\right\|_{\infty}=\mu>0 . \quad$ Also, (5.19), (5.21) yield length $\left(\pi_{n}[-d, d]\right)=\tau^{Z}(2 d)$ if $n \in M(Z)$. All this and (5.41) imply the existence of some $Z \in\{1,2,3, \ldots\}$ and some $n \in M(Z)$ satisfying

$$
\pi_{n}[-d, d] \times\left[\tau^{Z} a_{Z}, \tau^{Z} a_{Z}+\tau^{Z} r\right] \times\{0\} \times\left\{b_{Z}\right\} \subset V
$$

and $\tau^{-Z}\left\|f_{2}\right\|_{\infty}>N$. This last part, (5.4) and (4.60) enables us to write

$$
\tau^{-Z} f_{2}\left(x_{1}, x_{2}\right)>N, \text { hence } x_{1} \in[-d, d], \quad 0<x_{2} \leqq r
$$


for some $\left(x_{1}, x_{2}\right) \in \operatorname{spt}\left(f_{2}\right)$. From (5.47), (5.48) we get

$$
\left(\pi_{n}\left(x_{1}\right), \tau^{Z} a_{Z}+\tau^{Z} x_{2}, 0, b_{Z}\right) \in V .
$$

In addition, (5.35), (5.32), $x_{2}>0,(5.4),(5.23),(5.48)$ imply

$$
\begin{aligned}
& \left|v^{Z}\left(\pi_{n}\left(x_{1}\right), \tau^{Z} a_{Z}+\tau^{Z} x_{2}, 0, b_{Z}\right)\right|=\tau^{-Z}\left|u^{Z}\left(\tau^{-Z} \pi_{n}\left(x_{1}\right), x_{2}, 0,0\right)\right| \\
& \quad=\sum_{m \in M(Z)} \tau^{-Z}\left(f_{1}^{m}+f_{2}^{m}\right)\left(\tau^{-Z} \pi_{n}\left(x_{1}\right), x_{2}\right) \geqq \tau^{-Z} f_{2}^{n}\left(\tau^{-Z} \pi_{n}\left(x_{1}\right), x_{2}\right) \\
& \quad=\tau^{-Z} f_{2}\left(x_{1}, x_{2}\right)>N .
\end{aligned}
$$

Since $v^{Z}$ is $C^{\infty}$, we find that $\left|v^{Z}\right| \geqq N$ holds on a neighborhood of $\left(\pi_{n}\left(x_{1}\right), \tau^{Z} a_{Z}+\right.$ $\left.\tau^{Z} x_{2}, 0, b_{Z}\right)$. Combining this with (5.39) and (5.49), we obtain that $|u| \geqq N$ holds on a set $W \subset V$, where $W$ has positive Lebesgue measure.

Using Lemma 5.5, (5.35), (5.39), Lemma 5.8, (5.36), (5.40), Lemma 5.11, Lemma 5.12, Lemma 5.13, Lemma 5.14 and Lemma 5.15, we find that all of the properties listed in the theorem of Sect. 1 are satisfied when we make the following changes: $S$ is replaced by $S^{\prime},[0, \infty)$ is replaced by $[T, \infty), R^{3} \times\{1\}$ is replaced by $R^{3} \times\left\{\left(1-\tau^{2}\right)^{-1} T\right\}$, and (1.7) is replaced by Lemma 5.13. The proof is completed with a change of scale.

\section{References}

1. Caffarelli, L., Kohn, R., Nirenberg, L.: Partial regularity of suitable weak solutions of the Navier-Stokes equations. Commun. Pure Appl. Math. 35, 771-831 (1982)

2. Moran, P. A. P.: Additive functions of intervals and Hausdorff measure. Proc. Camb. Phil. Soc. 42, 15-23 (1946)

3. Scheffer, V.: Hausdorff measure and the Navier-Stokes equations. Commun. Math. Phys. 55, 97-112 (1977)

4. Scheffer, V.: A solution to the Navier-Stokes inequality with an internal singularity. Commun. Math. Phys. 101, 47-85 (1985)

Communicated by C. H. Taubes

Received August 29, 1986 
